

\title{
Asset Price Bubbles and Monetary Policy: Revisiting the Nexus at the Zero Lower Bound*
}

\author{
Jacopo Bonchi ${ }^{\dagger}$ \\ Sapienza University of Rome
}

May 7, 2020

\begin{abstract}
Asset price bubbles are a major source of macroeconomic instability, but can they play a stabilizing role in a low interest rates environment? To answer this question, I study an economy in which the natural rate of interest declines permanently and a long-lasting zero lower bound (ZLB) episode makes risk-free interest rates persistently low. Asset price bubbles redistribute wealth across generations because of the life-cycle pattern of net worth. In this way, they increase the natural interest rate by serving as a store of value for older cohorts and as a collateral for the younger ones, and the central bank can escape from the ZLB with consequent output gains. Therefore, the redistribution of wealth/consumption across generations, which would be welfare-reducing in normal times, becomes welfare-enhancing. However, asset price bubbles affect mainly the natural interest rate through their role of collateral, and a leveraged bubble is the most detrimental for output when it crashes (Jordá et al., 2015).
\end{abstract}

JEL Classification Numbers: E13, E44, E52

Keywords: Asset price bubbles; Natural interest rate; Zero lower bound

*I'm thankful for the useful comments to Giuseppe Ciccarone, Jordi Galì, Guido Ascari, Lorenza Rossi, Salvatore Nisticò, Enrico Marchetti, Luca Fornaro, Davide Debortoli, Alberto Martin, Vladimir Asriyan, and three anonymous referees.

$\dagger$ Sapienza University of Rome. Address: Department of Social and Economic Sciences, 5 Piazzale Aldo Moro, Rome, Italy, 00185. Email: jacopo.bonchi@uniroma1.it. 


\section{Introduction}

Asset price bubbles are not rare events in the advanced economies. In the postwar period, a stock bubble bust has occurred on average every 13 years, while a housing bubble bust every 20 years (IMF, 2003). Given the regularity of boom-and-bust cycles in asset prices and their detrimental consequences for the economy, the origins of bubbles have been largely investigated and, in particular, the literature has given much attention to the potential impact of monetary policy on the existence and the size of bubbles. This paper explores the other side of the relationship and it shows that asset price bubbles can affect significantly monetary policy by relaxing the zero lower bound constraint in a low interest rates environment.

The macroeconomic literature has widely studied the relationship between monetary policy and asset price bubbles starting from the late 1990s. At that time, the debate was about the role of monetary policy in dampening excessive fluctuations in asset prices viewed as a potential source of macroeconomic instability and financial crises. The conventional wisdom dictated that a flexible inflation targeting was the proper policy framework to maintain either price and financial stability, because asset price dynamics alters macroeconomic conditions mainly through their link with inflation (Bernanke and Gertler, 1999, 2001). On the other hand, many academics and policy makers challenged the prevailing view on theoretical and empirical grounds, arguing in favor of "lean against the wind" monetary policies that would mitigate large fluctuations in asset prices through interest rate increases (e.g., Cecchetti et al., 2000; Borio and Lowe, 2002).

This old and settled debate has been revived by the boom-and-bust cycle in the US housing market of the early 2000s, which has fostered a new flourishing literature. Yet, this new body of the literature is still developed along the old lines of research that focused on the impact of monetary policy on asset price bubbles, and it seems to not be adapted to the latest developments in the major advanced economies 1

In the last decades, most of the advanced economies has gone through a dramatic downward adjustment in the risk-free real and nominal interest rates. This adjustment has been driven mainly by the declining pattern of the "natural" interest rate. ${ }^{2}$ which is expected to become more pronounced

\footnotetext{
${ }^{1}$ Among the others, Ikeda (2013), Galì (2014, 2020) and Dong et al. (2017).

${ }^{2}$ The "natural" interest rate is the level of the real interest rate consistent with potential output and stable prices (Wicksell, 1898). Although not observable directly, it can be estimated through econometric techniques. Laubach and Williams (2016) show a downward trend in the US natural rate of interest starting from the 1980s, while Holston et al. (2017) estimate a similar decline for other industrialized economies (Canada, the Eurozone and the UK). These estimates refer to a mediumterm natural interest rate and point to a negative value only in the case of the Eurozone. However, taken a short-term definition, a negative value for the natural interest rate is strongly supported by the empirical evidence (e.g., Cúrdia, 2015), as well as being consistent with the risk-free real interest rate observed during and after the Great Recession.
} 
Figure 1: Assets and liabilities for age cohorts in the US
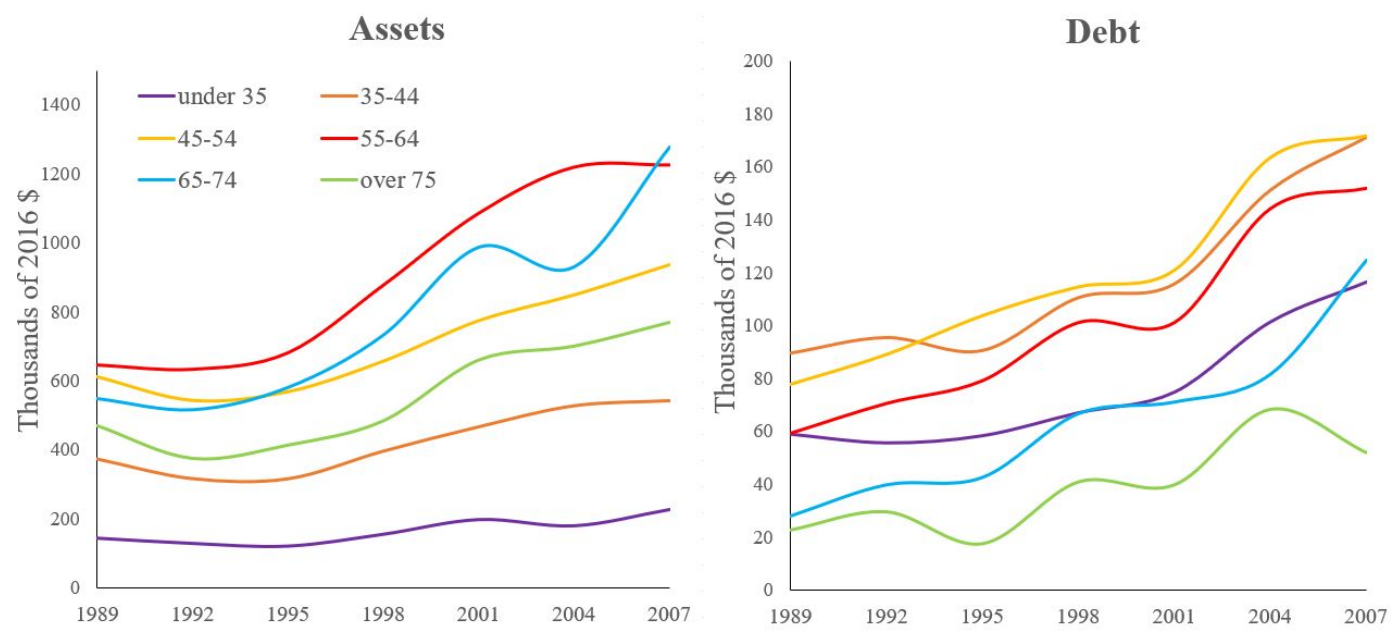

Source: Survey of Consumer Finances (SCF) Chartbook 2016.

Note: For a definition of assets and liabilities in the SCF see Bricker et al. (2017).

because of the COVID-19 pandemic (Jordá et al., 2020), leading to persistently low risk-free interest rates also in the future. The persistence of low interest rates exposes the economy to the risk of more frequent zero lower bound (ZLB) episodes because, in the case of a negative shock, monetary policy would not have sufficient margin to cut the policy rate, and the resulting recession would be deeper and longer than usual (Kiley and Roberts, 2017). Against this backdrop, another largely unexplored aspect of the relationship between monetary policy and asset price bubbles becomes relevant: the potential impact of bubbles on the nominal interest rate.

The intuition is straightforward. Wealth gains from asset price bubbles are unevenly distributed across generations due to the life-cycle pattern of assets and debt. During bubbly episodes, the older cohorts with large asset holdings experience a massive increase in net worth, which, among the others, discourages saving. On the other hand, younger cohorts have a low stock of wealth that increases only slightly, but they are more prone to borrow and can take on higher debt via appreciated collaterals. This is exactly what happened in the US in the decade before the Great Recession, when stocks and houses appreciated strongly due to the emergence of the so-called "dot-com bubble" and the housing bubble (Figure 11, 3 As asset price bubbles redistribute wealth across generations by

\footnotetext{
${ }^{3}$ In that period, it is worthy to note that the personal saving rate declined from $6.3 \%$ in 1994 to $3 \%$ in 2007 (FRED data). Furthermore, fluctuations in net worth were driven by the parallel fluctuations in asset prices (Aizcorbe et al., 2003; Bucks et al., 2009).
} 
serving as a store of value and as a collateral, they can reduce the supply of saving and foster the demand for borrowing, absorbing the excess of saving underlying a low/negative natural interest rate. The relevance of this theoretical mechanism at the ZLB is the main object of the present paper, which aims to show that purely redistributive bubbles affect macroeconomic aggregates in a low interest rates environment, unlike in normal times.

To that aim, I develop an overlapping generations (OLG) model that accounts for the life-cycle behavior of saving and net worth. Agents live for three periods: when young, they are borrowers; in middle age, they save for retirement; once retired, they consume all the proceeds from saving. As only middle-aged households get a positive income, they supply funds to young households in exchange for a risk-free bond. The natural interest rate is accordingly determined by credit demand and supply, and it can be permanently negative. Labor and goods markets are perfectly competitive, but a downward nominal wage rigidity that makes monetary policy non-neutral is assumed. Asset price bubbles, formalized as intrinsically worthless assets, can emerge rationally in this economy, but what is relevant is not the "rational" nature of the bubbles, rather their twofold role of store of value and collateral through which they influence the natural interest rate. The effect of bubbles going through the natural rate of interest has radically different implications for macroeconomic outcomes whether the central bank is constrained or not by the ZLB.

In normal times, the natural interest rate is not negative and the economy lies in a steady state equilibrium with output at the potential and inflation at the target, because the ZLB is not binding. When asset price bubbles emerge, they increase the natural interest rate by absorbing excess saving and fostering borrowing, but this results in higher real and nominal interest rates without affecting macroeconomic outcomes. On the other hand, a higher natural interest rate underlies a redistribution of resources from young households to old ones that is welfare-reducing.

These results are overturned when the ZLB is binding and the economy is stuck in a low interest rates equilibrium. If the natural interest rate turns negative in a bubbleless economy, a too low inflation target prevents the central bank from driving the real interest rate to its natural level, and a long-lasting ZLB episode makes risk-free nominal and real interest rates persistently low, as well as to cause negative output and inflation gaps. Starting from this equilibrium, the upward pressure of bubbles on the natural interest rate drives the nominal interest rate in non-negative/positive territory, and this affects macroeconomic outcomes because the central bank can now escape from the ZLB. As a consequence, all generations benefit from the bubble because of the higher output/consumption and the bubble is welfare-enhancing. 
My benchmark model highlights a stabilizing role for asset price bubbles, before their bursting, when the ZLB binds. This stands in contrast with the well-known destabilizing role of the bubble bursting in normal times, pointing to a potential trade-off for the policy makers in a low interest rates environment: asset price bubbles can improve macroeconomic conditions today at the cost of a more likely and deeper recession tomorrow, when they crash.

However, the nature of this trade-off in terms of output gains/losses could be different according to the bubble type, because an unleveraged bubble that does not foster credit is less likely to trigger a severe recession than a leveraged bubble accompanied by a credit boom (Jordá et al., 2015). To account for the different bubble types that could arise with low interest rates, I augment my benchmark model with an exogenous probability of bubble bursting and an incomplete credit market. This extended model clarifies what is, whether store of value or collateral, the role of the bubble that influences mostly the natural interest rate, and provides some preliminary notions about the different output gains/losses associated with the two bubble types.

An unleveraged bubble serves only as a store of value, unlike a leveraged one that is a collateral. While an unleveraged bubble increases the natural rate of interest, but it does not drive it in positive territory leaving the central bank stuck at the ZLB, a leveraged bubble delivers a nonnegative/positive natural interest rate and so the monetary authority can escape from the ZLB.

The rest of the paper is structured as follows. Section 2 presents the related literature. I spell out my benchmark model with monetary policy and rational bubbles in Section 3, and I describe the major results in Section 4. Then, I extend my benchmark model to the case of unleveraged and leveraged bubbles in Section 5. Section 6 concludes.

\section{Related Literature}

My paper builds on the models of rational bubbles, in which bubbly assets emerge to mitigate the inefficiency in the financial market resulting from a shortage of investment opportunities (e.g., Samuelson, 1958; Tirole, 1985) or credit market frictions (e.g., Martin and Ventura, 2011, 2012; Fahri and Tirole, 2012; Miao and Wang, 2018; Bengui and Phan, 2018). However, my framework distinguishes from these models for the introduction of non-neutral monetary policy and its central role. In this respect, the papers closest to mine are Galì $(2014,2020)$ and Asriyan et al. (2019). Galì $(2014,2020)$ formalizes monetary policy in terms of an interest rate rule, but he investigates the traditional relationship that runs from the policy rate to asset price bubbles, without accounting for the 
relationship running in the opposite direction at the ZLB. My paper also differs from that of Asriyan et al. (2019) in two key dimensions. First, the central bank conducts the monetary policy through the issuance of unbacked money (public bubbles) in their framework. Hence, though a high growth rate of money/inflation makes money unattractive as a store of value bringing the economy out of a liquidity trap, their mechanism does not rely on the natural interest rate and its effect on the ZLB constraint. Indeed, and this is the second difference, they do not study an economic environment with persistently low interest rates, because the liquidity trap is an outcome of a bubble crash, not the result of structural forces putting downward pressure on the natural interest rate. This respect relates my work to the recent large literature on secular stagnation.

Unlike the traditional literature on liquidity traps that studies ZLB episodes caused by temporary shocks (e.g., Krugman, 1998; Eggertsson and Woodford, 2003) or self-fulfilling expectations (e.g., Behnabib et al., 2001), the new secular stagnation theory views recent long-lasting ZLB episodes as a result of the structural decline in the natural interest rate driven by slow-moving forces (Summers, 2014; Baldwin and Teulings, 2014; Gordon, 2015; Eggertsson et al., 2016; Bacchetta et al., 2016; and Eggertsson et al., 2019). I stick to this theory for the interpretation of the current low interest rates environment. In particular, I enrich the theoretical model of Eggertsson et al. (2019) with rational asset bubbles to emphasize a potentially stabilizing role for them in such an environment. Bacchetta et al. (2016) also find that bubbles can bring the economy out of the ZLB, but their result relies on a supply-side mechanism through capital accumulation, not on a demand-side one trough the redistribution of wealth. Furthermore, they do not disentangle the effect of unleveraged and leveraged bubbles at the ZLB.

\section{The Model Economy}

I consider a three-period OLG economy without capital. The generation born at $t$ is composed by $N_{t}$ agents and the constant ratio between the size of the young and middle generations is $(1+g)=$ $\frac{N_{t}}{N_{t-1}}$, where $g$ is also the population growth rate. The economy consists of three agents who form expectations rationally and are perfectly informed: households, firms and a central bank in charge of monetary policy; and two markets for financial assets: the credit and bubbles markets.

I will describe the behavior of the agents and the functioning of the asset markets in this section. 


\subsection{Households}

Households have a positive income, $Y_{t}=\frac{W_{t}}{P_{t}} L_{t}+\frac{Z_{t}}{P_{t}}$, only in middle age when they supply inelastically their labor endowment $\bar{L}$ for a wage $W_{t}$ and run firms whose profits are $Z_{t}{ }^{4}$ Therefore, they exchange financial assets to transfer resources across generations. When young, households borrow to consume by issuing a one-period risk-free bond, while middle-aged households supply funds. The middle generation can also buy from the old generation different varieties of bubbles introduced by the previous cohorts. Each period, middle-aged households create $\delta \in(0,1)$ units of a variety of "bubble", whose price is $P_{t \mid t}^{B} \geq 0$, though the bubbly asset is intrinsically worthless ${ }^{5}$ The quantity of bubbly assets grows at the same rate as the population ${ }^{6}$ but a fraction $\delta$ of old bubbly assets is destroyed each period. Bubbles (either new and old ones) allow agents to carry over funds to old age, but new bubbles also improve the ability to repay debt in middle age. Young households, who face the exogenous debt limit $D$, can accordingly demand more funds in the credit market by using the future bubble as collateral.

The representative household solves the maximization problem:

$$
\max _{C_{t+1}^{m}, C_{t+2}^{o}, Q_{t+1 \mid t+1-j}^{B}} E_{t}\left\{\ln C_{t}^{y}+\beta \ln C_{t+1}^{m}+\beta^{2} \ln C_{t+2}^{o}\right\}
$$

s.t.

$$
\begin{gathered}
C_{t}^{y}=B_{t}^{y} \\
C_{t+1}^{m}=Y_{t+1}+\delta P_{t+1 \mid t+1}^{B}-\left(1+r_{t}\right) B_{t}^{y}-B_{t+1}^{m}-\sum_{j=0}^{\infty} P_{t+1 \mid t+1-j}^{B} Q_{t+1 \mid t+1-j}^{B} \\
C_{t+2}^{o}=\left(1+r_{t+1}\right) B_{t+1}^{m}+(1-\delta)(1+g) \sum_{j=0}^{\infty} P_{t+2 \mid t+1-j}^{B} Q_{t+1 \mid t+1-j}^{B} \\
\left(1+r_{t}\right) B_{t}^{y}=D+\delta E_{t} P_{t+1 \mid t+1}^{B} .
\end{gathered}
$$

\footnotetext{
${ }^{4}$ Labor demand $L_{t}$ can differ from labor supply $\bar{L}$ because of the binding downward wage rigidity, which causes labor rationing like in Schmitt-Grohé and Uribe (2016). I address this issue more in deep in the next sections.

${ }^{5}$ As pointed out by Martin and Ventura (2011) in a similar setting, a bubble is a claim on future savings, because it entitles the owner to receive a payment from the next generation. Middle-aged households issue directly this claim by initiating a new bubble, while they buy the claims issued by the past generations by purchasing old bubbles. For real-world examples of bubbly assets, see Martin and Ventura (2012).

${ }^{6}$ Although this assumption is necessary to guarantee that each middle-aged household owns one unit of bubbly assets overall (the sum of the quantities of all the bubble varieties is one), its effect on the aggregate value of the bubble is neutralized fully by normalizing the bubble index in terms of $N_{t-1}$, which is the aggregate bubble supply. In general, my results are unaffected by this assumption. This is shown in the Appendix A.1 where I provide a modified version of the model in which population growth is zero; there exists a fixed unit supply of bubbly assets in aggregate and the economy still grows at a positive rate because of productivity growth.
} 
The household's utility, which is discounted at the rate $\beta$, is given by the real consumption of each generation, $C_{t}^{i}$ with $i=y, m, o . B_{t}^{y}$ and $B_{t}^{m}$ denote respectively the real value of bonds issued by the young generation and bought by the middle one. The (gross) rate of return on bonds is $\left(1+r_{t}\right)$. $Q_{t \mid t-j}^{B}$ and $P_{t \mid t-j}^{B}$ are the quantity at time $t$ of the bubbly asset introduced by the cohort $t-j$ and its price. $Q_{t \mid t-j}^{B} P_{t \mid t-j}^{B}$ is accordingly the expenditure for the bubbly asset $t-j$ from the middle generation, whose total expenditure for all the varieties of bubbles is given by the summation in equation (2). Equation (4) is the debt limit that is binding by assumption for young households? 7 The optimality conditions for the household's problem are

$$
\frac{1}{C_{t}^{m}}=\beta\left(1+r_{t}\right) E_{t} \frac{1}{C_{t+1}^{o}}
$$

and

$$
P_{t \mid t-j}^{B}=(1-\delta)(1+g) \beta E_{t}\left[\left(\frac{C_{t}^{m}}{C_{t+1}^{o}}\right) P_{t+1 \mid t-j}^{B}\right] .
$$

Condition (5) is a standard Euler equation, while equation (6) expresses the price at time $t$ of the bubbly asset introduced at $t-j$. The bubbly asset has no fundamental value, but it is valued if the household expects to gain profit from selling it, hence its current price depends on the discounted expected price in the next period.

\subsection{Firms}

Firms operate for just one period in a perfectly competitive market. As their number is equal to the size of the middle generation, the economy's growth rate is $g$. The technology of firms is described by the production function

$$
Y_{t}=L_{t}^{\alpha}
$$

where $L_{t}$ is the quantity of labor employed and $0<\alpha<1$. Taking the price of goods $\left(P_{t}\right)$ and that of labor $\left(W_{t}\right)$ as given, firms maximize their profit

$$
Z_{t}=P_{t} Y_{t}-W_{t} L_{t}
$$

\footnotetext{
${ }^{7}$ This holds for

$$
D<\frac{1}{1+(1+\beta) \beta}\left[Y_{t}-\beta(1+\beta) \delta P_{t \mid t}^{B}\right],
$$

a condition that is met in all the simulations presented in the paper.
} 
subject to 7 . The resulting optimality condition is the labor demand

$$
\frac{W_{t}}{P_{t}}=\alpha L_{t}^{\alpha-1}
$$

The labor market is perfectly competitive, but workers are unwilling to accept nominal wages lower than a minimum level (Schmitt-Grohé and Uribe, 2016). The downward nominal wage rigidity (DNWR), which makes monetary policy non-neutral ${ }^{8}$ is expressed as

$$
W_{t}=\max \left(\gamma \Pi^{*} W_{t-1}, P_{t} \alpha \bar{L}^{\alpha-1}\right)
$$

where $\gamma \in(0,1]$ and $\gamma \Pi^{*} \geq 1$. The first term in the max operator denotes the minimum wage workers are willing to accept, which is a fraction $\gamma$ of the past nominal wage indexed to the gross inflation target $\Pi^{*} \geq 1$, while the second term is the "flexible" wage level compatible with full employment. When labor market clearing requires an increase in $W_{t}$ from the last period by at least $\gamma \Pi^{*}$, the nominal wage is flexible, and there is full employment $\left(L_{t}=\bar{L}\right)$. When the wage should increase by less than $\gamma \Pi^{*}$ to maintain the full employment of resources, the downward wage rigidity prevents such price adjustment and involuntary unemployment arises $\left(L_{t}<\bar{L}\right)$.

\subsection{The Central Bank}

The central bank behaves according to the interest rate rule

$$
1+i_{t}=\max \left[1,\left(1+r_{t}^{f}\right) \Pi^{*}\left(\frac{\Pi_{t}}{\Pi^{*}}\right)^{\phi_{\pi}}\right],
$$

where $\phi_{\pi}>1$ and the gross inflation rate is given by $\Pi_{t}=P_{t} / P_{t-1}$. The central bank maneuvers the nominal interest rate $i_{t}$ to track the natural interest rate $r_{t}^{f}$, which is consistent with potential output $\left(Y^{f}=\bar{L}^{\alpha}\right)$ and inflation at the targeted level $\Pi^{*}$ (Cúrdia et al., 2015). However, if the natural interest rate turns negative $\left(1+r_{t}^{f}<1\right)$ and the targeted inflation rate is not sufficiently high, the central bank would set a negative nominal interest rate but it cannot because of the ZLB in equation (11). Finally, the gross real interest rate has to satisfy the Fisher condition

$$
1+r_{t}=\left(1+i_{t}\right) E_{t} \Pi_{t+1}^{-1},
$$

\footnotetext{
${ }^{8}$ The structure of the model is unchanged with the alternative assumption of Calvo pricing (Calvo, 1983), as shown in a similar setting by Eggertsson et al. (2019).
} 
where $E_{t}$ denotes the expectation operator.

\subsection{Credit and Bubbles Markets}

Bubbly assets market clearing requires

$$
Q_{t \mid t-j}^{B}=\delta(1-\delta)^{j}
$$

The demand for the bubble variety $t-j$ at time $t$ has to be equal to its supply, which depends on the quantity of the variety created by each middle-aged household in $t-j$ and on that which survives over time. Given the assumption on the endowment of new bubbles and those on destruction and growth rates of old bubbles, the total amount of bubbles in the economy is equal to the size of the middle generation 9 The economy's bubble index, which includes new and old bubbles, is

$$
P_{t}^{B}=\frac{1}{N_{t-1}} \delta \sum_{j=0}^{\infty}(1-\delta)^{j} P_{t \mid t-j}^{B},
$$

while the index for old bubbles only is

$$
B_{t}=\frac{1}{N_{t-1}} \delta \sum_{j=1}^{\infty}(1-\delta)^{j} P_{t \mid t-j}^{B} .
$$

Both indexes are normalized in terms of the size of the middle generation, $N_{t-1}$. The equation for the aggregate bubble index can be rewritten as

$$
P_{t}^{B}=U_{t}+B_{t}=(1+g)\left[\frac{B_{t+1}}{\left(1+r_{t}\right)}\right]
$$

by using equations (5), (6), 14) and (15). By assuming perfect foresight, I disregard here and afterwards the expectation term. Equation $\left[16\right.$, in which $U_{t}=\delta P_{t \mid t}^{B} / N_{t-1}$ denotes the value of

${ }^{9}$ The growth rate of the quantity of bubbly assets and the size of middle and old generations do not appear in equation [13, because they cancel out each other. For example, the equilibrium condition at time $t$ for the bubble variety $t-1$ is

$$
\begin{aligned}
N_{t-1} Q_{t \mid t-1}^{B} & =N_{t-2}(1+g)(1-\delta) \delta \\
Q_{t \mid t-1}^{B} & =(1-\delta) \delta .
\end{aligned}
$$

Given [13], the total quantity of bubbly assets is

$$
N_{t-1} Q_{t}^{B}=N_{t-1} \sum_{j=0}^{\infty} Q_{t \mid t-j}^{B}=N_{t-1},
$$

which means that each middle-aged household owns overall one unit of all bubble varieties. 
the new bubbly assets, is a no-arbitrage condition. New and old bubbly assets will be valued from rational agents in the next period if their expected rate of return is equal to that of bonds, that is the real interest rate. The term $(1+g)$ undoes the effect of the growth in the quantity of bubbles on their total value, which depends accordingly only on their price (see footnote 6).

The equilibrium in the credit market requires the amount of funds demanded equals that supplied, given the different size of young households and middle-aged ones:

$$
(1+g) B_{t}^{y}=B_{t}^{m}
$$

Denote credit demand with $D_{t}^{c}$ and credit supply with $S_{t}^{c}$. Plugging (4) into credit demand obtains

$$
D_{t}^{c}=\left(\frac{1+g}{1+r_{t}}\right)\left(D+U_{t+1}\right) .
$$

Combining 2, (3), 4, , 5, and (16) yields the credit supply 10

$$
S_{t}^{c}=\frac{\beta}{1+\beta}\left(Y_{t}-D-U_{t}-B_{t}\right)-\frac{1}{1+\beta}\left(B_{t}+U_{t}\right)
$$

which can be rewritten more compactly as

$$
S_{t}^{c}=\frac{\beta}{1+\beta}\left(Y_{t}-D\right)-\left(B_{t}+U_{t}\right)
$$

Equations (18) and (19) describe the twofold role of the bubble in our economy. First, bubbles serve as a store of value, reducing the supply of saving in the credit market (19). An alternative investment vehicle diverts resources away from risk-free bonds ( $B_{t}$ in the first term on the righthand side) and it induces to save less by providing an additional income $\left(B_{t}+U_{t}\right.$ in the second term) in old age. Second, future bubbly assets $U_{t+1}$ serve as a collateral fostering demand for borrowing in (18). Higher demand for credit from young households results in a higher debt to repay for middle-aged ones, and this decreases also the credit supply $\left(U_{t}\right.$ in the first term on the right-hand side of (19)).

\footnotetext{
${ }^{10}$ We derive

$$
\sum_{j=0}^{\infty} P_{t \mid t-j}^{B} Q_{t \mid t-j}^{B}=U_{t}+B_{t}
$$$$
(1-\delta) \sum_{j=0}^{\infty} P_{t+1 \mid t-j}^{B} Q_{t \mid t-j}^{B}=B_{t+1}
$$

from 13, 14 and 15 
Figure 2: Equilibrium in the credit market

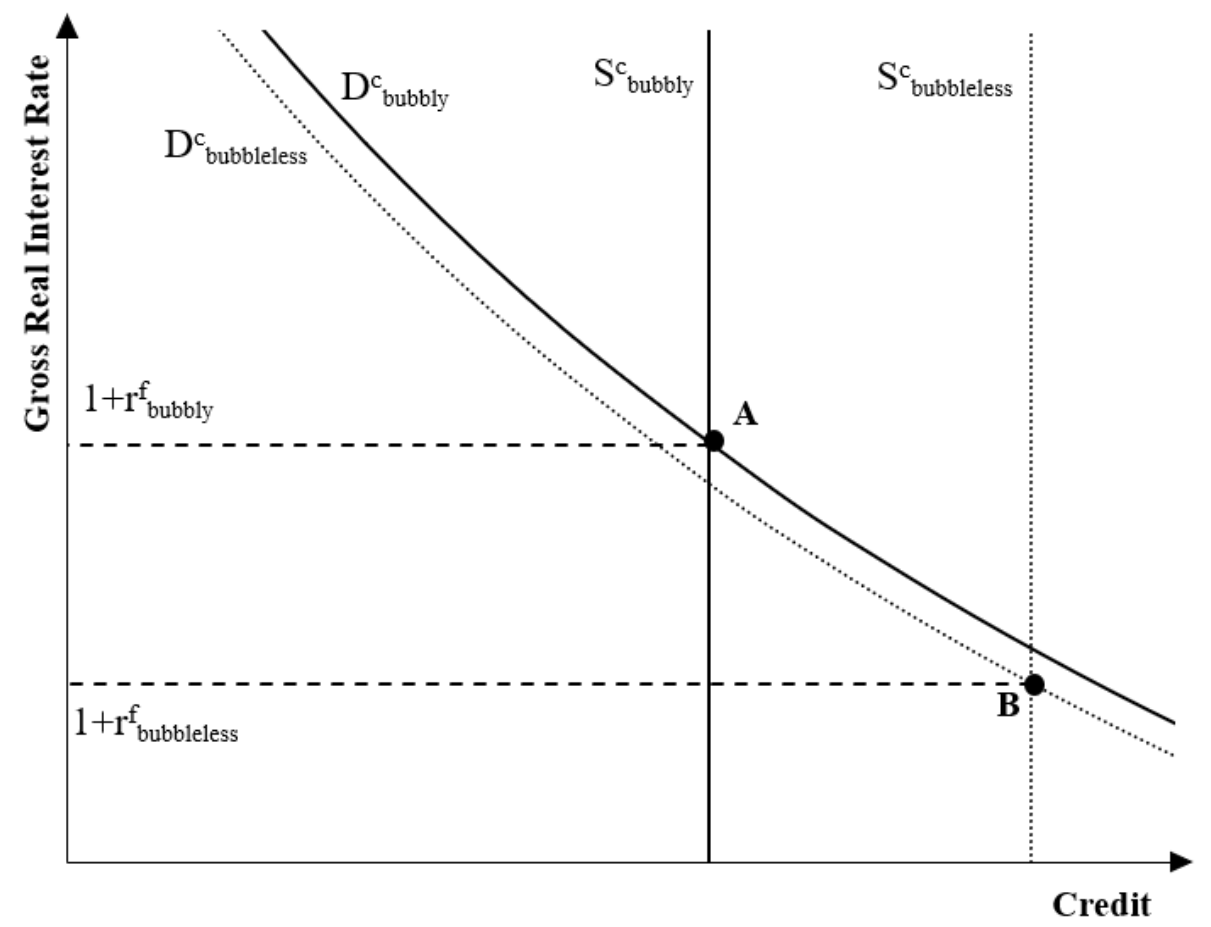

The real interest rate that clears the credit market,

$$
\left(1+r_{t}\right)=(1+g)\left[\frac{(1+\beta)\left(D+U_{t+1}\right)}{\beta\left(Y_{t}-D-U_{t}-B_{t}\right)-\left(B_{t}+U_{t}\right)}\right]
$$

can be derived by equating (18) and (19), and it corresponds to the natural interest rate,

$$
\left(1+r_{t}^{f}\right)=(1+g)\left[\frac{(1+\beta)\left(D+U_{t+1}\right)}{\beta\left(Y^{f}-D-U_{t}-B_{t}\right)-\left(B_{t}+U_{t}\right)}\right]
$$

at the potential level of production. The two channels, through which the bubble alters the natural rate of interest, are depicted graphically in Figure 2 The figure plots the credit demand and supply curves either in a bubbleless economy $\left(B_{t}=U_{t}=0\right)$ and in a bubbly one. Compared to a bubbleless economy, bubbly assets reduce credit supply and foster demand for credit. As these two effects push $r_{t}^{f}$ up by shifting the credit supply curve left and the credit demand curve right, the natural rate of interest is higher in a bubbly economy ${ }^{11}$ This result will be crucial in the next sections, in which I

\footnotetext{
${ }^{11}$ I deliberately isolate the redistributive effect of asset price bubbles from any other one, in particular from that affecting
} 
will study the effect of a permanent change to $r_{t}^{f}$.

\section{Steady State Equilibrium}

A perfect foresight equilibrium is a set of quantities $\left\{C_{t}^{y}, C_{t}^{m}, C_{t}^{o}, B_{t}^{y}, B_{t}^{m}, Y_{t}, Z_{t}, L_{t}, B_{t}\right\}$ and

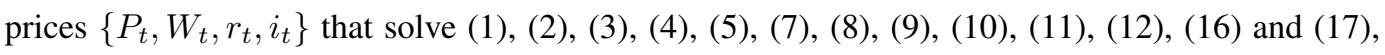
given $\left\{U_{t}\right\}$ and initial values for $W_{-1}, B_{-1}^{m}$ and $B_{-1}$. I assume $U_{t}=U$ with $U \geq 0$. Then, we obtain the law of motion of the old bubble by combining 16 and 21 and taking $Y_{t}=Y$ as given 12

$$
B_{t+1}=\frac{(1+\beta)(D+U)\left(U+B_{t}\right)}{\beta\left(Y-D-U-B_{t}\right)-\left(U+B_{t}\right)}=H\left(B_{t}, U\right) .
$$

A bubbleless steady state equilibrium corresponds to the pair $(B, U)=(0,0)$ such that $B=$ $H(0,0)=0$, while a bubbly steady state equilibrium is given by a pair $(B, U)$ satisfying $B=$ $H(B, U)$ with $B \in\left(0, Y^{f}\right)$. The bubbly equilibrium exists if

$$
D<\frac{\beta}{1+\beta}(Y-D)
$$

which is a necessary and sufficient condition. A too low debt limit prevents young households from issuing enough bonds to absorb all savings. This pushes the real interest rate below the economy's growth rate in a bubbleless economy, and in fact condition 23. can be rewritten as

$$
(1+g)\left[\frac{(1+\beta) D}{\beta(Y-D)}\right]=1+r_{n b}<1+g
$$

where $r_{n b}$ is the real interest rate when bubbles are not valued. Under such circumstances, rational agents find profitable to invest in intrinsically worthless assets (Samuelson, 1958; Tirole, 1985). More precisely, when condition 23 is satisfied, there exists a continuum of stable $\left(B^{S}(U), U\right)$ and unstable $\left(B^{U}(U), U\right)$ bubbly equilibria for any $U \in[0, \bar{U}){ }^{13}$ In what follows I restrict my attention

output through capital accumulation. The introduction of capital, along with risk-free bonds, would imply a higher natural interest rate, which could be negative anyway in a bubbleless economy. Furthermore, the impact of bubbles on the natural interest rate going through the redistributive channel is unchanged, as formally proved in Appendix A.2. The extended model of the Appendix, among the others, sheds lights on the proper interpretation of the bubbly and risk-free assets in my model.

${ }^{12}$ The way in which output is determined in steady state is outlined in Section 4.1

${ }^{13} \mathrm{~A}$ formal proof for condition 23 is given in Appendix B.1 in which I depict stable and unstable equilibria and the old bubble dynamics (Figure 6. The stability of the bubbly equilibrium depends on the condition $\partial H(B, U) / \partial B<1$, which also guarantees the stationarity of the old bubble, as proved in Appendix B.2 The existence of the bubble, as well as its stationarity, is verified in all the simulations reported in the paper. Finally, the condition $r<g$ has to be met even in a bubbly equilibrium, because the price of old bubbles grows at the rate of $r$ and, given the presence of new bubbles, the aggregate bubble would grow unboundedly if $g=r$. There is accordingly an upper bound on $B$ like in Galì (2014). This is the value 
to the stable bubbly equilibrium.

In the rest of the section, I study a bubbly full employment equilibrium in comparison with two different bubbleless equilibria: a full employment equilibrium with a positive nominal interest rate and an equilibrium with output below the potential and low real and nominal interest rates because of binding ZLB. Asset price bubbles can emerge in both the bubbleless equilibria, but I aim to investigate whether their effect on macroeconomic outcomes and welfare varies according to the original bubbleless steady state.

\subsection{Asset Price Bubbles and the ZLB}

\subsubsection{Bubbleless Economy}

The steady state equilibrium can be expressed by aggregate demand and supply, which consist of two regimes. The regime of aggregate supply (AS) is determined by equation (10) through the inflation rate. If $\Pi \geq \gamma \Pi^{*}$, the flexible nominal wage is higher (or equal) than (to) the minimum wage in (10) and the labor market clears. Supply corresponds to potential output and it can be computed from equations (7), (9) and (10):

$$
Y_{A S}=\bar{L}^{\alpha}=Y^{f} .
$$

On the contrary, if the minimum wage imposed by the DNWR is higher than the flexible level, nominal wages cannot adjust to clear the labor market and price/wage inflation is

$$
\Pi=\gamma \Pi^{*},
$$

while output and employment are determined by demand. Equations (24) and (25) are depicted respectively as a vertical and a horizontal segment in Figure 3

The regime of aggregate demand (AD) is governed by equation (11) through the ZLB. Combining equations (11), (12), and (21) yields the following $\mathrm{AD}$ with a positive policy rate $(1+i>1)$ :

$$
Y_{A D}=D+\left(\frac{1+\beta}{\beta}\right)\left(\frac{1+g}{1+r^{f}}\right)\left(\frac{\Pi^{*}}{\Pi}\right)^{\phi_{\pi}-1} D .
$$

for which the real interest rate equals the growth rate of the economy, namely

$$
B^{U}(0)=\frac{\beta}{1+\beta}(Y-D)-D .
$$


Figure 3: FE and LIR equilibria

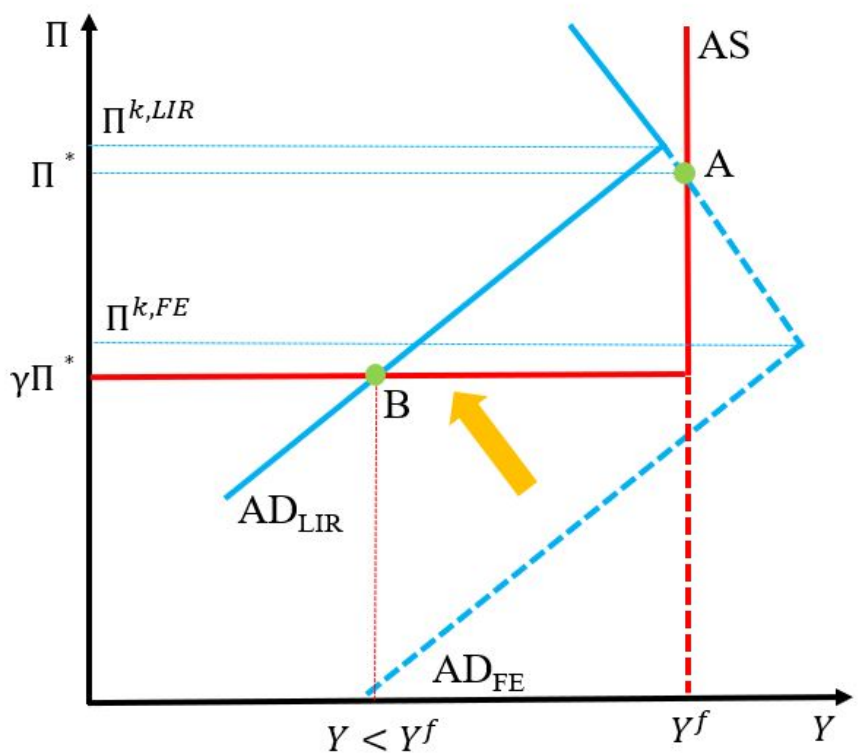

If $1+i=1$, we get a different $\mathrm{AD}$ from the equations above:

$$
Y_{A D}=D+\left(\frac{1+\beta}{\beta}\right)(1+g) \Pi D
$$

Demand is negatively related to inflation in equation 26] and it is depicted by a downward sloping AD curve in Figure $3{ }^{14}$ Equation 27 in contrast relates positively aggregate demand and inflation, and it takes the shape of an upward sloping AD curve in the same figure. If the ZLB is not binding, the central bank raises more than proportionally the policy rate $(\phi>1)$ in response to an inflation increase. This raises the real interest rate, contracting demand and so stabilizing inflation. Ordinary monetary policy tools are inhibited at the ZLB, in which the real interest rate depends only on the inflation level through the Fisher equation (12). Therefore, an inflation increase decreases the real interest rate and expands demand. The inflation level at which the central bank hits the ZLB, $\Pi^{k}$, is depicted as a kink in the AD curve and is computed by equating the two arguments in the right-hand side of (11):

$$
\Pi^{k}=\left[\frac{1}{\left(1+r^{f}\right)}\right]^{\frac{1}{\phi_{\pi}}} \Pi^{* \frac{\phi_{\pi}-1}{\phi_{\pi}}} .
$$

\footnotetext{
${ }^{14}$ For the sake of exposition, I follow Eggertsson et al. (2019) in plotting the downward sloping AD curve as linear, though it is in general non-linear. Of course, my results would be the same with the general non-linear representation.
} 
The AD kink is an indicator of the risk of a ZLB episode: for a given inflation target, the lower is $\Pi^{k}$, the lower is the risk of hitting the ZLB because a sufficiently high $r^{f}$ gives the central bank enough space to cut the policy rate if necessary.

Figure 3 shows that two different bubbleless equilibria are possible according to the value of the natural interest rate. If the natural interest rate is non-negative in a bubbleless economy, $1+r_{n b}^{f} \geq 1$, the central bank can steer the policy rate to keep output at the potential and inflation at the target. The economy stays at the steady state equilibrium $A$, which corresponds to the curve $A D_{F E}$ and features $r_{n b}=r_{n b}^{f} \geq 0, i \geq 0, Y=Y^{f}$ and $\Pi=\Pi^{*}$. This equilibrium is referred to as "full employment equilibrium" (hereafter FE). In contrast, if a permanent change to $r^{f}$ occurs and the resulting level of the natural interest rate falls deeply in negative territory so that

$$
1+r_{n b}^{f}<\frac{1}{\Pi^{*}}<1
$$

the ZLB is binding and is associated with output losses. The AD curve moves, with the AD kink, from $A D_{F E}$ to $A D_{L I R}$ and the new equilibrium is $B$, which features $r_{n b}^{f}<r_{n b}<0, i=0$, $Y<Y^{f}$ and $\Pi=\gamma \Pi^{*} \leq \Pi^{*}$. It is accordingly a "low interest rates equilibrium" (hereafter LIR) because the ZLB episode is associated with low nominal and real interest rates ${ }^{15}$ When the inflation target is not sufficiently high to drive the real interest rate to its negative natural level, monetary policy is constrained by the ZLB and it cannot keep output at the potential level and inflation at the targeted level. The LIR equilibrium is a stylized representation of the macroeconomic conditions in the major industrialized economies for most of the last decade and, presumably, for the next years, given the unfolding global recession triggered by the COVID-19 pandemic (IMF, 2020).

\subsubsection{Bubbly Economy}

As long as $r_{n b}$ falls below $g$, a rational bubble can emerge in both the bubbleless equilibria considered. As bubbly assets have redistributive purposes, they do not alter aggregate supply compared to

\footnotetext{
${ }^{15}$ Given $1+r^{f} \geq 1$ and $\gamma \Pi^{*} \geq 1, \Pi^{*} \geq 1 / \gamma\left(1+r^{f}\right)$ and so the FE equilibrium is unique, while the LIR exists and it is unique because $1+r^{f}<1 / \Pi^{*}<1$ (Ascari and Bonchi, 2019). Furthermore, the determinacy of the FE is guaranteed by the Taylor principle $\left(\phi_{\pi}>1\right)$, while the LIR equilibrium is determinate because

$$
\frac{\alpha}{1-\alpha} \frac{Y}{Y-D}>0
$$
}

A formal derivation of the condition for the determinacy of the LIR is available upon request. 
Figure 4: FEB equilibrium

Panel A

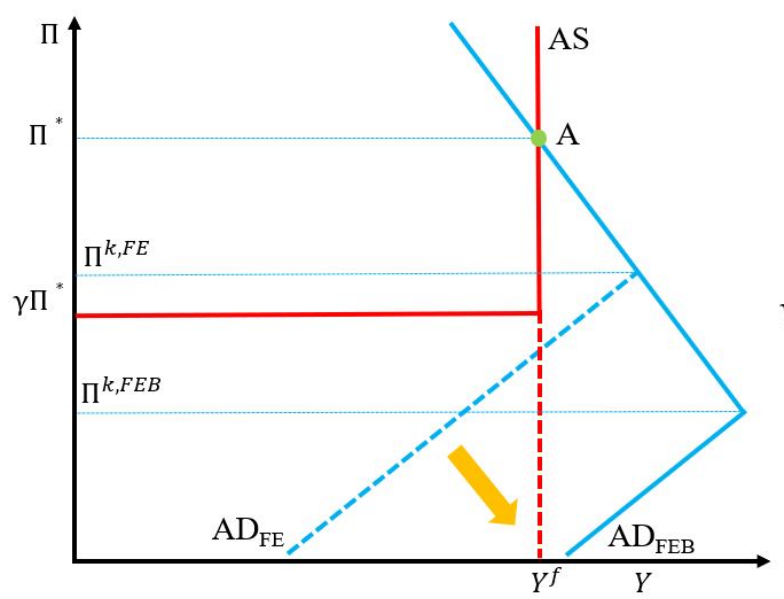

Panel B

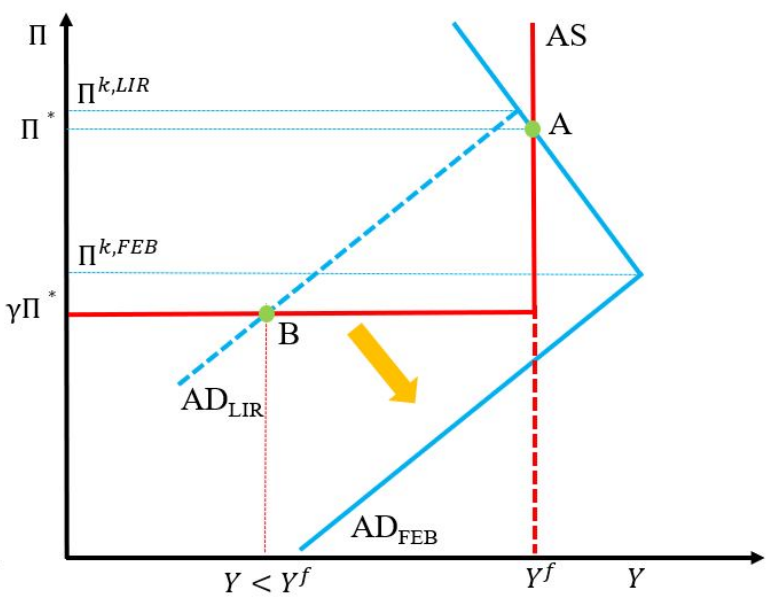

the last section, but only aggregate demand. It becomes

$$
Y_{A D}=D+\left(\frac{1+\beta}{\beta}\right)(U+B)+\left(\frac{1+\beta}{\beta}\right)\left(\frac{1+g}{1+r^{f}}\right)\left(\frac{\Pi^{*}}{\Pi}\right)^{\phi_{\pi}-1}(D+U)
$$

for a positive policy rate and

$$
Y_{A D}=D+\left(\frac{1+\beta}{\beta}\right)(U+B)+\left(\frac{1+\beta}{\beta}\right)(1+g) \Pi(D+U)
$$

in case of binding ZLB. More importantly, the equation of the AD kink is still given by (28), but the natural interest rate is higher and $\Pi^{k}$ is consequently lower in a bubbly economy than in a bubbleless one. This means the positive effect of asset price bubbles on the natural interest rate, studied in Section 3.4, strongly mitigates the risk of hitting the ZLB for any given inflation level. Although the impact of bubbles on the ZLB constraint is overshadowed in normal times when the economy lies in a full employment equilibrium and the central bank can maneuver freely the policy rate, its importance emerges in a LIR environment when the binding ZLB causes output losses. This difference stands out in Figure 4, in which the transition from a FE (Panel A) and from a LIR (Panel B) to a "full employment bubbly equilibrium" (hereafter FEB) is depicted. The transitional dynamics is trivial because the economy reaches immediately a FEB, once the old bubble $B$ is at its positive steady state value. 
If the bubble originates in the $\mathrm{FE}$, the new $\mathrm{AD}$ kink, $\Pi^{k, F E B}$, shifts the upward sloping $\mathrm{AD}$ curve down from $A D^{F E}$ to $A D^{F E B}$, but nothing changes substantially and, in fact, the FE and the FEB occur at the same point $A$ (Panel A). The emergence of bubbly assets cannot affect macroeconomic aggregates, rather it raises the natural interest rate leading to higher real and nominal interest rates. The resulting extra space to maneuver the policy rate cannot be exploited by the central bank in normal times, but it becomes essential in an LIR equilibrium. In such an environment, though redistributive bubbles cannot per se alter macroeconomic outcomes, they can drive the natural interest rate in non-negative/positive territory,

$$
1+r^{f} \geq 1
$$

and the central bank can consequently escape from the ZLB. This is depicted in Panel B of Figure 4. The $\mathrm{AD}$ curve shifts from location $A D_{L I R}$ to $A D_{F E B}$ and, as a consequence, the economy moves from the original LIR equilibrium $B$ to the FEB equilibrium $A$, in which $i>0, Y=Y^{f}$ and $\Pi=\Pi * 1617$

\subsection{Welfare Analysis}

As macroeconomic aggregates vary only if the economy moves from the LIR to the FEB, the welfare implications of asset price bubbles could differ whether the central bank is stuck initially at the ZLB or not. Here, I compare the allocation of resources and the welfare implied by the FEB with first those corresponding to the FE and then to those resulting from the LIR. The subscripts FE, LIR and $F E B$ denote the variables and welfare, measured by lifetime utility, in the equilibria under investigation.

\footnotetext{
${ }^{16}$ The FEB is unique under the same condition as the FE: $\Pi^{*} \geq 1 / \gamma\left(1+r^{f}\right)$. Hence, given $\gamma \Pi^{*} \geq 1$, a strictly nonnegative natural interest rate guarantees the existence and uniqueness of the FEB. Only in the special case of $1+r^{f}=\Pi^{*}=$ 1 , the central bank hits the ZLB in the FEB, notwithstanding it can stabilize inflation and output $\left(Y=Y^{f}\right.$ and $\left.\Pi=\Pi^{*}\right)$. Finally, condition 31. guarantees to reach the new equilibrium even if the DNWR depends on the level of employment (Ascari and Bonchi, 2019, Appendix A.2).

${ }^{17}$ The transition to the FEB does not require an excessively large aggregate bubble to occur, because the minimum/necessary bubble size is $2.7 \%$ of GDP and wealth is $11.8 \%$ higher in the FEB compared to the LIR. A standard calibration of the model consistent with the recent estimates of the natural interest rate delivers these figures (Appendix B.3. To give an order of magnitude, the ratio of Wealth-to-GDP has been approximately twice as large (100\% greater) the Capital-to-GDP ratio in the US over the last decade (Piketty, Saez, and Zucman, 2018).
} 


\subsubsection{FE vs FEB}

The variables relevant for the allocation of resources in the FE are:

$$
\begin{aligned}
\left(1+r_{F E}\right) & =\frac{(1+g)(1+\beta) D}{\beta\left(Y^{f}-D\right)} \\
B_{F E}^{y} & =\frac{D}{1+r_{F E}} \\
B_{F E}^{m} & =\frac{\beta}{1+\beta}\left(Y^{f}-D\right) \\
C_{F E}^{y} & =B_{F E}^{y}=\frac{1}{1+g}\left[\frac{\beta}{1+\beta}\left(Y^{f}-D\right)\right] \\
C_{F E}^{m} & =\frac{1}{1+\beta}\left(Y^{f}-D\right) \\
C_{F E}^{o} & =(1+g) D .
\end{aligned}
$$

The first three equations have been derived in Section $3.4(B=U=0$ in this case). The last three equations are computed from (1), 22 and (3) by substituting for $\left(1+r_{F E}\right), B_{F E}^{y}$ and $B_{F E}^{m}\left(=S_{F E}^{c}\right)$. The middle-aged agent saves a constant share of income net of debt, while the remaining share is consumed. The young generation receives savings in exchange for risk-free bonds, but its size is larger than that of the middle generation. This reduces the amount $B_{F E}^{y}$ each young household raises in the credit market and so the individual consumption $C_{F E}^{y}$. As one-period bonds are assets for the middle-aged households and liabilities for the young ones, the representative agent pays down the total amount of debt $D$ to the elderly in middle age. Old households are fewer than middle-aged ones and this increases their proceeds from lending.

In the FEB, the same variables become:

$$
\begin{aligned}
\left(1+r_{F E B}\right) & =\frac{(1+g)(1+\beta)(D+U)}{\beta\left(Y^{f}-D-U-B\right)-(U+B)} \\
B_{F E B}^{y} & =\frac{D+U}{1+r_{F E B}} \\
B_{F E B}^{m} & =\frac{\beta}{1+\beta}\left(Y^{f}-D\right)-(U+B) \\
C_{F E B}^{y} & =B_{F E B}^{y}=\frac{1}{1+g}\left[\frac{\beta}{1+\beta}\left(Y^{f}-D\right)-(U+B)\right] \\
C_{F E B}^{m} & =\frac{1}{1+\beta}\left(Y^{f}-D\right) \\
C_{F E B}^{o} & =(1+g)(D+U+B) .
\end{aligned}
$$


They can be computed by following the same steps as above. The real interest rate is higher and less credit is supplied in a bubbly economy, while young households demand more credit by pledging the new bubbles. Bubbly collateral increases the debt repaid to old households (the term $U$ in the last equation), whose consumption increases further because of their bubbly investment in middle age (the term $B$ ). On the other hand, an increased demand for credit does not necessarily cause a higher $C^{y}$ in the FEB, rather $C_{F E B}^{y}$ is lower than $C_{F E}^{y}$ because of the lower credit supply. Young households demand more funds and pay down more debt when middle-aged, but they just have higher interest payments without raising more funds. Finally, the consumption of the middle-aged household is identical to that in the FE, because the positive and negative effects of bubbles cancel out. The additional income provided by the bubbly investment in old age changes the intertemporal allocation of consumption, because it induces middle-aged households to save less, freeing up resources to consume $((U+B) /(1+\beta))$. These resources are fully exhausted by the higher debt to repay and by the old bubble purchases.

The different allocation of consumption across generations implies distinct welfare levels in the two equilibria considered. Welfare is measured by the lifetime utility of the representative agent and it is computed by substituting for the consumption of each generation into the utility function. The difference between $U_{F E B}$ and $U_{F E}$ is

$$
U_{F E B}-U_{F E}=\ln \left[1-\frac{1+\beta}{\beta} \frac{(U+B)}{\left(Y^{f}-D\right)}\right]+\beta^{2} \ln \left(1+\frac{U+B}{D}\right) .
$$

It depends on the differential levels of $C^{y}$ and $C^{o}$ in the two steady states, which reflect the negative impact of bubbles on the consumption of young households (the first term on the right-hand side) and their positive effect on the consumption of old ones (the second term). The magnitude of these two effects, which determines the sign of the difference in 32 , varies according to $\beta, D$ and the size of the aggregate bubble $P^{B}=U+B$. Therefore, I perform several calibrations of the parameters and the bubble size to establish the sign of (32) on firm numerical grounds. These numerical exercises, which are illustrated in Appendix B.4. point to an overall negative effect of bubbles on lifetime utility when the economy moves from the FE to the FEB. 


\subsubsection{LIR vs FEB}

The allocation of resources in the LIR is expressed by the following variables:

$$
\begin{aligned}
\left(1+r_{L I R}\right) & =\frac{1}{\gamma \Pi^{*}}=\frac{(1+g)(1+\beta) D}{\beta(Y-D)} \\
B_{L I R}^{y} & =\frac{D}{1+r_{L I R}} \\
B_{L I R}^{m} & =\frac{\beta}{1+\beta}(Y-D) \\
C_{L I R}^{y} & =B_{L I R}^{y}=\frac{1}{1+g}\left[\frac{\beta}{1+\beta}(Y-D)\right] \\
C_{L I R}^{m} & =\frac{1}{1+\beta}(Y-D) \\
C_{L I R}^{o} & =(1+g) D .
\end{aligned}
$$

The consumption of the old generation is exactly the same as the FE and, more generally, the shape of the functional relationships is unchanged with respect to the FE. Yet, the LIR differs from the other bubbleless equilibrium because of a lower output. As a consequence, the emergence of bubbles in the LIR still redistributes resources across generations, but now the redistribution affects indirectly macroeconomic outcomes through the ZLB constraint, with substantially different implications for welfare. To explain this result, I report again here the variables in the FEB:

$$
\begin{aligned}
\left(1+r_{F E B}\right) & =\frac{(1+g)(1+\beta)(D+U)}{\beta\left(Y^{f}-D-U-B\right)-(U+B)} \\
B_{F E B}^{y} & =\frac{D+U}{1+r_{F E B}} \\
B_{F E B}^{m} & =\frac{\beta}{1+\beta}\left(Y^{f}-D\right)-(U+B) \\
C_{F E B}^{y} & =B_{F E B}^{y}=\frac{1}{1+g}\left[\frac{\beta}{1+\beta}\left(Y^{f}-D\right)-(U+B)\right] \\
C_{F E B}^{m} & =\frac{1}{1+\beta}\left(Y^{f}-D\right) \\
C_{F E B}^{o} & =(1+g)(D+U+B) .
\end{aligned}
$$

As the income of the elderly depends on the return from risk-free and bubbly assets, not on aggregate activity, the old generation benefits equally from the bubble independently of the original bubbleless equilibrium. In contrast, middle-aged households are directly affected by the increase in output in the FEB because their income and consumption raise relative to the LIR, while the consumption of 
young households can increase or decrease according the relative strength of two opposing effects. The two effects are evident in the difference

$$
\begin{aligned}
C_{F E B}^{y}-C_{L I R}^{y} & =\frac{1}{1+g}\left[\frac{\beta}{1+\beta}\left(Y^{f}-Y\right)-(U+B)\right] \\
& =\frac{1}{1+r_{F E B}^{f}}\left\{D\left[1-\gamma \Pi^{*}\left(1+r_{F E B}^{f}\right)\right]+U\right\},
\end{aligned}
$$

where the second equality can be obtained by using 27) and 29) to substitute respectively for $Y$ and $Y^{f}$. The aggregate bubble, $U+B$, reduces the amount supplied to young households to consume, but the supply of credit can be anyway higher in the FEB because of the higher income available to save $\left(Y^{f}>Y\right)$. As the sign of 33 cannot be determined analitically, but it depends on the calibrations of $D, \gamma \Pi^{*},\left(1+r_{F E B}^{f}\right)$ and $U$, I carry out a numerical exercise, which can be found in Appendix B.4 This exercise shows unambiguously that 33 is positive and so even the consumption of young households increases when the economy moves from the LIR to the FEB.

To sum up, a bubble emerging in the FE is welfare-reducing because it redistributes consumption from the young generation to the old one, and the welfare losses in young age are greater than the welfare gains in old age. In contrast, a bubble arising in the LIR allows indirectly the economy to escape from the ZLB, with a consequent increase in output that raises the consumption and welfare levels of all generations, not only the old one.

\section{The Model Economy: Unleveraged vs Leveraged Bubble}

The results from the previous section emphasize the output gains from the emergence of an asset price bubble in a low interest rates environment, but an exhaustive analysis of bubbly episodes requires to account also for the potential output losses from the bubble bursting. In this section, I take a step in this direction by investigating what role of bubbles, whether a store of value or collateral, influences mainly the natural interest rate is crucial. Indeed, real-world bubbles are often purely unleveraged or purely leveraged, and this difference carries significant consequences in terms of output losses, because the leveraged bubble bust is the most detrimental according to the empirical evidence.

To study unleveraged versus leveraged bubbles in a low interest rates environment, I extend the benchmark model of Section 3 in several dimensions, and the major innovation regards the two markets for financial assets. I alter the structure of the financial markets so that also young 
households buy the bubble when they want to borrow against it. The bubble is accordingly leveraged in this case, while it is unleveraged when the middle-aged households use the bubbly asset to carry over resources to the old age. Furthermore, I abstract from population growth and normalize the size of generations to 1, but firms and the monetary authority behave as in the benchmark model.

Market for bubbles: there exists one variety of bubbles in fixed unit supply. As there is a "old" bubble only and no bubble creation (and destruction), young households have to participate directly in the market, along with the middle-aged households, if they want to borrow against the bubble. Therefore, the equilibrium condition in the market for bubbles is

$$
Q_{t}^{B, y}+Q_{t}^{B, m}=1
$$

where $Q_{t}^{B, y}$ and $Q_{t}^{B, m}$ are respectively the bubble purchases of young and middle-aged households. The price of the bubble, $\hat{P}_{t}^{B}$, is stochastic because each period there is a constant probability $\rho \in$ $[0,1)$ the price collapses to 0 and, if the bubble has already collapsed, it cannot re-emerge again (Weil, 1987). Conditioning on not having crashed, the price of the bubble is $\hat{P}_{t}^{B}=P_{t}^{B}>0$.

Credit market: The young generation collects resources for consumption in the credit market, which clears when (17) holds with $g=0$. However, this market is now incomplete because young households issue a one-period non-contingent debt contract that is defaultable 18 In the event of default, old households, who lent funds to young ones in middle age, can repossess only a "fundamental" collateral $D \in(0, Y)$ and a "bubbly" collateral, which is given by a fraction $\phi$ of the young households' bubble holdings (Bengui and Phan, 2018).

Given the structure of the financial markets, the household's problem becomes:

$$
\max _{C_{t+1}^{m}, C_{t+2}^{o}, Q_{t}^{B, y} \geq 0, Q_{t+1}^{B, m} \geq 0} E_{t}\left\{\ln C_{t}^{y}+\beta \ln C_{t+1}^{m}+\beta^{2} \ln C_{t+2}^{o}\right\}
$$

subject to:

$$
\begin{gathered}
C_{t}^{y}=B_{t}^{y}-\hat{P}_{t}^{B} Q_{t}^{B, y} \\
C_{t+1}^{m}=Y_{t+1}+\hat{P}_{t+1}^{B}\left(Q_{t}^{B, y}-Q_{t+1}^{B, m}\right)-B_{t+1}^{m}-\left(1-\xi_{t+1}\right)\left(1+r_{t}\right) B_{t}^{y}-\xi_{t+1}\left(D+\phi \hat{P}_{t+1}^{B} Q_{t}^{B, y}\right) \\
C_{t+2}^{o}=\left(1-h_{t+2}\right)\left(1+r_{t+1}\right) B_{t+1}^{m}+\hat{P}_{t+2}^{B} Q_{t+1}^{B, m} \\
\left(1+r_{t}\right) B_{t}^{y}=D+\phi P_{t+1}^{B} Q_{t}^{B, y} .
\end{gathered}
$$

\footnotetext{
${ }^{18} \mathrm{~A}$ microfoundation for this contract is given by Ikeda and Phan (2016). I assume the real return from bonds does not depend on the size of the loan, like Allen and Gale (2000).
} 
The notation is the same of Section 3, but now the representative household chooses the optimal bubble holding, which can be 0 or positive, either in young and middle age ${ }^{19}$ Furthermore, middleaged households optimally choose to default or not at time $t+1$ according to the rule

$$
\xi_{t+1}= \begin{cases}0 & \text { if }\left(1+r_{t}\right) B_{t}^{y} \leq D+\phi \hat{P}_{t+1}^{B} Q_{t}^{B, y} \\ 1 & \text { if }\left(1+r_{t}\right) B_{t}^{y}>D+\phi \hat{P}_{t+1}^{B} Q_{t}^{B, y} .\end{cases}
$$

The default function $\xi_{t+1}$ is 0 in case of repaying, when defaulting is the most costly option, while $\xi_{t+1}=1$ corresponds to defaulting and it occurs when this option is more convenient than repaying. As the borrowing limit in equation (5) is given by the amount can be repossessed in case of default, the middle generation opts for defaulting when the bubble bursts. Indeed, if this occurs, old households can only garnish $D$ from middle-aged ones because $\tilde{P}_{t+1}^{B}=0$. The remaining fraction of the original claims is a loss, namely the haircut $h_{t+1}$ :

$$
h_{t+1}= \begin{cases}0 & \xi_{t+1}=0 \\ 1-\frac{D}{\left(1+r_{t}\right) B_{t}^{m}} & \left.\xi_{t+1}=1 \quad \text { (default }\right) .\end{cases}
$$

I study the problem of the representative household in steady state by distinguishing a fully unleveraged bubbly equilibrium from a fully leveraged bubbly one. The bubble is fully unleveraged when the middle generation only owns it for investment purposes $\left(Q_{t}^{B, m}=1\right.$ and $\left.Q_{t}^{B, y}=0\right)$. The bubble is accordingly a store of value, but not a collateral. In contrast, the bubble is fully leveraged when the young generation buys all the bubble because of its collateral value $\left(Q_{t}^{B, m}=0\right.$ and $\left.Q_{t}^{B, y}=1\right)$. Therefore, the bubble is only a collateral. To analyze these two steady state equilibria and so to study the bubble types in isolation, I have to choose a specific calibration of $\phi$ for each equilibrium. For $\phi=0$, borrowing against bubbly assets is not possible, and the bubble is fully unleveraged by construction, while the bubble is fully leveraged for $\phi=1$ because of its high collateral value, which induces young households to demand the entire supply of bubbles 20

\footnotetext{
${ }^{19}$ The borrowing constraint, which could be alternatively written as $\left(1+r_{t}\right) B_{t}^{y}=D+\phi \max \left\{\hat{P}_{t+1}^{B}\right\} Q_{t}^{B, y}$, is binding either if the bubble cannot be or can be fully collateralized because $[1+\beta(1+\beta)] D<Y_{t}$ and

$$
D<\frac{1+\beta}{1+\beta(1+\beta)(1-\rho)}\left\{\frac{1}{1+\beta} Y_{t+1}+\beta(1-\rho)\left[P_{t}^{B}\left(1+r_{t}\right)-P_{t+1}^{B}\right]\right\}
$$

${ }^{20}$ Young households could demand bubbly assets too for $\phi=0$ because these are complex securities that play for them the twofold role of collateral and store of value. However, considering $Q_{t}^{B, y}>0$ would complicate the analysis without altering the fully unleveraged nature of the bubble. On the other hand, $\phi=1$ implies that the price of the bubble, carried over to middle age, is fully exhausted by the higher debt to repay, and the bubble can be used as a collateral only. A formal proof that the bubble is fully leveraged for $\phi=1$ is available upon request.
} 


\subsection{Steady State Equilibrium}

The steady state equilibrium is bubbleless for $P^{B}=0$, while it is bubbly for $P^{B}>0$. The bubbleless economy is identical to that in Section 4 In particular, I focus on leveraged and unleveraged bubbles that could emerge in the LIR and allow the economy to escape from the ZLB by affecting the natural interest rate. The transitional dynamics is again trivial because of the absence of capital and the equilibrium considered, either unleveraged or leveraged, is the only asymptotic bubbly equilibrium $\left(\lim _{t \rightarrow \infty} P_{t}^{B}>0\right)$.

\subsubsection{Asset Price Bubbles and the ZLB: Unleveraged Bubble}

For $\phi=0$, the bubble cannot be collateralized and there is no default risk $(\xi=h=0)$. Given $Q^{B, y}=0$, the budget constraint in young age is $C^{y}=B^{y}=D /(1+r)$. The household faces instead the following constraints in middle and old age:

$$
\begin{gathered}
C^{m}=\left\{\begin{array}{lll}
Y-B^{m}-(1+r) B^{y} & \text { bubble bursting } \\
Y-P^{B} Q^{B, m}-B^{m}-(1+r) B^{y} & \text { bubble } & \text { survival },
\end{array}\right. \\
C^{o}=\left\{\begin{array}{lll}
(1+r) B^{m} & \text { bubble } & \text { bursting } \\
(1+r) B^{m}+P^{B} Q^{B, m} & \text { bubble } & \text { survival, }
\end{array}\right.
\end{gathered}
$$

Therefore, the optimality conditions of the household's problem are

$$
\frac{1}{Y-P^{B} Q^{B, m}-B^{m}-(1+r) B^{y}}=\beta(1+r)\left[\rho \frac{1}{(1+r) B^{m}}+(1-\rho) \frac{1}{(1+r) B^{m}+P^{B} Q^{B, m}}\right]
$$

and

$$
\frac{1}{Y-P^{B} Q^{B, m}-B^{m}-(1+r) B^{y}}=\beta(1-\rho) \frac{1}{(1+r) B^{m}+P^{B} Q^{B, m}},
$$

which express the optimal choice of bonds and bubbles from middle-aged households. We can derive $P^{B U}$, where the superscript $U$ denotes an unleveraged bubble, and the corresponding real interest rate in a fully unleveraged bubbly equilibrium $\left(Q_{t}^{B, m}=1\right)$ by using these optimality conditions, the borrowing constraint and the equilibrium condition for the credit market:

$$
\begin{aligned}
P^{B U} & =(1-\rho) \frac{\beta}{1+\beta}(Y-D)-D \\
(1+r) & =\frac{(1+\beta) D}{\rho \beta(Y-D)+(1+\beta) D}<1
\end{aligned}
$$


Figure 5: LIR and unleveraged bubble

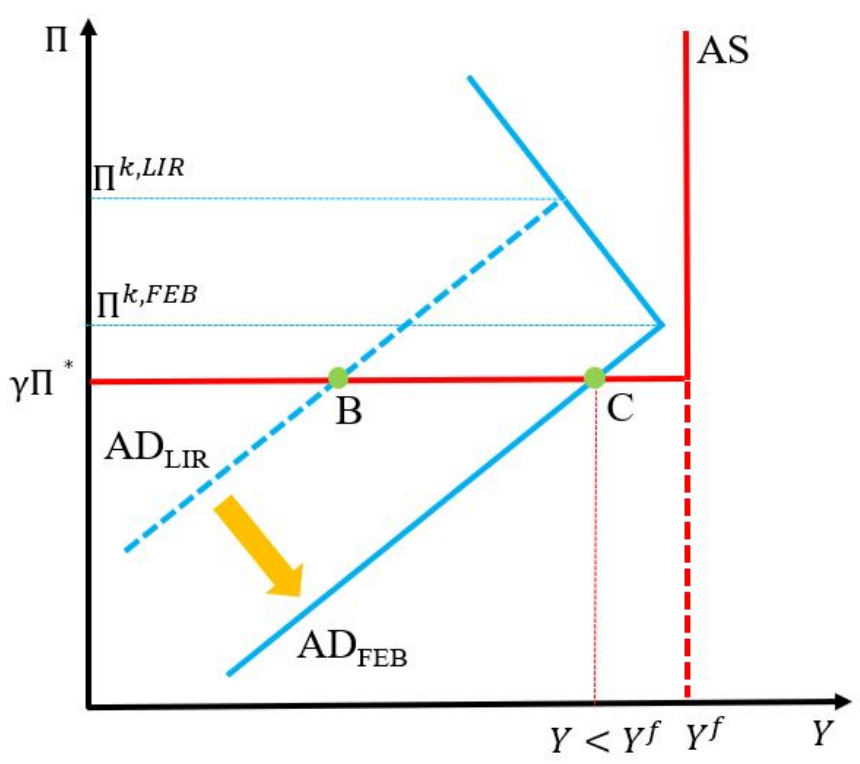

A major result stands out from these two equations. Looking at the first equation, the unleveraged bubbly equilibrium exists $\left(P^{B U}>0\right)$ only if $1-\rho>1+r_{n b}=(1+\beta) D / \beta(Y-D)$, a standard condition for rational stochastic bubbles (e.g., Bengui and Phan, 2018). As the real interest rate is negative in the initial LIR, a fully unleveraged bubble can arise. More importantly, the unleveraged bubble does not make the natural interest rate, which is given by the second equation at $Y=Y^{f}$, non-negative/positive like in (31). This means the increase in the natural interest rate engineered by the bubble, does not drive the economy out of the ZLB as depicted in Panel B Figure 4 and so output and inflation gaps are still negative. However, the economy moves from the LIR to a new equilibrium, in which output increases slightly because a higher natural interest rate reduces the real interest rate gap (Figure 5$)^{21}$

\footnotetext{
${ }^{21}$ For $\gamma \Pi^{*}>1$ and $\gamma<1$, a special case emerges if $1+r^{f}<1$ and $1 /\left(1+r^{f}\right)<\Pi^{*}<1 / \gamma\left(1+r^{f}\right)$ (Ascari and Bonchi, 2019). In this case, the unleveraged bubble makes a FEB to arise, along with a bubbly equilibrium with full employment and binding ZLB, but the LIR survives. As a consequence, three equilibria exist and a multiplicity problem arises.
} 


\subsubsection{Asset Price Bubbles and the ZLB: Leveraged Bubble}

Given $\phi=1$, the budget constraint in young age is $C^{y}=B^{y}-P^{B} Q^{B, y}$ with $B^{y}=(D+$ $\left.P^{B} Q^{B, y}\right) /(1+r)$, while the budget constraint in middle age becomes

$$
C^{m}=\left\{\begin{array}{lrl}
Y-B^{m}-D & \text { bubble } & \text { bursting } \\
Y+P^{B} Q^{B, y}-B^{m}-(1+r) B & \text { bubble } & \text { survival. }
\end{array}\right.
$$

The young households only can buy the bubble $\left(Q^{B, y}=1\right.$ and $\left.Q^{B, m}=0\right)$. Hence, the budget constraint in old age is $C^{o}=(1-h)(1+r) B^{m}$, and middle-aged households invest all their savings in bonds, with their optimal choice expressed by equation (5). The other optimality conditions of the representative household are

$$
\begin{gathered}
\frac{1}{C^{y}}=\beta(1-\rho)\left[\frac{1}{Y+P^{B} Q^{B, y}-B^{m}-(1+r) B^{y}}\right]+\lambda^{D} \\
\lambda^{D}=\frac{1}{C^{y}(1+r)}-\beta(1-\rho)\left[\frac{1}{Y+P^{B} Q^{B, y}-B^{m}-(1+r) B^{y}}\right]>0
\end{gathered}
$$

where $\lambda^{D}$ is the lagrangian multiplier associated with the borrowing constraint, and it has to be positive because the household is borrowing constrained in young age. Combining these two conditions, the Euler equation (5) and the credit market clearing condition obtains

$$
P^{B L}=\frac{\beta}{1+\beta}(Y-D)-D
$$

and

$$
1+r=1+r^{f}=1
$$

where the superscript $L$ denotes a leveraged bubble. Either the condition for the existence of the bubble and the real interest rate prevailing in the bubbly economy differs from the case of an unleveraged bubble. A fully leveraged bubble in fact emerges under a looser condition than a fully unleveraged one 22 This condition, for which $P^{B L}>0$, is $1>1+r_{n b}$ and it is certainly satisfied in a LIR featuring a negative real interest rate. On the other hand, while an unleveraged bubble is not able to drive the natural interest rate in positive territory, the leveraged bubble pushes the originally negative natural interest rate up to 0 . As the central bank can now stabilize output at the potential

\footnotetext{
${ }^{22} \mathrm{I}$ do not report in the main text the shape of the $\mathrm{AD}$ in the two bubbly equilibria because it still given by 29 , and 30 , taking $P^{B}=B$ and $U=0$ for the unleveraged bubble and $P^{B}=U$ and $B=0$ for the leveraged one.
} 
and inflation at the target, the economy escapes from the LIR and moves to a FEB, as shown in the Panel B of Figure $4{ }^{23}$ This result relies on the specific nature of the leveraged bubble.

As young households own the bubble, they can shift the risk of the bubble bursting by borrowing against it, and the risk-shifting distinguishes a leveraged bubble starkly from an unleveraged one. Middle-aged households invest their income in an unleveraged bubble only if the bubble survival is enough likely and so the risk of the bubble bursting is sufficiently low $\left(1-\rho>1+r_{n b}\right)$. Unlike middle-aged households, young households do not bear the cost of the bubble bursting and can invest even in extremely risky bubbles. As a consequence, the probability of bursting $\rho$ does not enter in the condition for the emergence of a leveraged bubble $\left(1>1+r_{n b}\right)$. Furthermore, the risk-shifting behavior induces the young generation to invest heavily in the leveraged bubble, whose price/size is accordingly larger than that of the unleveraged one $\left(P^{B L}>P^{B U}\right)$, with a consequent more substantial upward pressure on the natural interest rate.

\section{Conclusions}

The present paper investigates the relationship between monetary policy and asset price bubbles, exploring the possibility that such a relationship runs from the bubble to monetary policy at the ZLB on the nominal interest rate. The focus is on the redistribution of wealth, engineered by an asset price bubble, across age cohorts and resulting increase in the natural interest rate, which could mitigate the ZLB constraint in a low interest rates environment. While I conduct the analysis through a theoretical OLG model that, though highly stylized, accounts for the life-cycle behavior of net worth and the current low interest rates environment in the industrialized economies.

When the nominal interest rate is positive, the redistributive role of bubbles is not relevant for macroeconomic outcomes. Instead, it hurts the consumption of the young cohort with consequent welfare losses. When the ZLB binds, this role instead becomes prominent because a higher natural interest rate gives the central bank extra margin to maneuver the policy rate, with resulting output

\footnotetext{
${ }^{23}$ These results confirm and reinforce the earlier intuitions derived from Bonchi (2019) in a two-period OLG model. In such a setting, he finds similar conditions for the existence of levareged and unleveraged bubbles, but he shows that even the unleveraged bubble can bring the economy to a full employment equilibrium, though only under very strict conditions. If $g>0$, the leveraged bubble would make the natural interest rate strictly positive, namely $1+r^{f}=1+g$, while we would obtain

$$
1+r^{f}=(1+g) \frac{(1+\beta) D}{\rho \beta\left(Y^{f}-D\right)+(1+\beta) D}
$$

for the unleveraged bubble. Hence, in a fully unleveraged bubbly equilibrium, the natural interest rate can be still negative $\left(1+r^{f}<1\right)$ if the probability of bubble bursting $\rho$ is high and/or the economy's growth rate is low. As bubbly episodes last few quarters and $g$ has been recently very low in the advanced economies, this is the most likely case.
} 
and welfare gains. This effect going through the natural interest rate relies on the twofold role of the bubble as a store of value and collateral, and it highlights a stabilizing role for asset price bubbles at the ZLB. However, the output gains from the emergence of the bubble are necessarily traded with future output losses when the bubble collapses. Concerning this point, I also show that the leveraged bubble, which is the most dangerous, is also the most beneficial in terms of output gains, as opposed to the unleveraged bubble.

The paper sheds light on the stabilizing role for asset price bubbles at the ZLB, which parallels, though in the opposite direction, the conventional view of bubbly episodes as a source of macroeconomic instability. In this respect, it is a first critical step in the analysis of the consequent trade-off for the policy makers, but, at least, three further steps are necessary for a complete analysis of the output gains/losses from asset price bubbles at the ZLB. First, temporary bubbly episodes should be explicitly studied. A three-period OLG model suggests that the output gains from bubbly episodes go hand-in-hand with the output losses, because the bubble type that increases mostly output is also the most detrimental for it when it bursts (Jordá et al., 2015). Notwithstanding, I just study a bubble that survives in the steady state equilibrium, without evaluating the output losses from the bubble bursting. Second, boom-and-bust cycles in asset prices can trigger financial crises, and the model should be accordingly augmented with a banking sector to account for a "financial accelerator" mechanism that could amplify output losses. Third, the trade-off from bubbly episodes at the ZLB should be studied within a richer model such as a "perpetual youth" OLG model (e.g., Galì, 2020). Indeed, in a standard OLG model, the interpretation of a period as the length of generation (that is twenty or thirty years) is not appropriate for analyzing bubbly episodes that last just a few quarters.

\section{References}

[1] Aizcorbe, Ana, Kennickell, Arthur and Kevin Moore. 2003. "Recent Changes in U.S. Family Finances: Evidence from the 1998 and 2001 Survey of Consumer Finances”, Federal Reserve Bulletin, A1, 95.

[2] Allen, Frank, and Douglas Gale. 2000. "Bubbles and crises", Economic Journal, 110 (460): 236-255.

[3] Ascari, Guido, and Jacopo Bonchi. 2019. “(Dis)Solving the ZLB Equilibrium Through Income Policies", Working Papers 10/19, Sapienza University of Rome, DISS. 
[4] Asriyan, Vladimir, Fornaro, Luca, Martin, Alberto and Jaume Ventura. 2019. "Monetary Policy for a Bubbly World”, CEPR Discussion Papers no. 13803.

[5] Bacchetta, Philippe, Kenza Benhima, and Yannick Kalantzis. 2016. "Money and Capital in a Persistent Liquidity Trap”, CEPR Discussion Papers no. 11369.

[6] Baldwin, Richard, and Coen Teulings. 2014. "Secular Stagnation: Facts, Causes and Cures", Ebook, VoxEU.

[7] Bengui, Julien, and Toan Phan. 2018. "Asset Pledgeability and Endogenously Leveraged Bubble", Journal of Economic Theory, 177: 280-314.

[8] Benhabib, Jess, Stephanie, Schmitt-Grohé and Martin Uribe. 2001. "The Perils of Taylor Rules", Journal of Economic Theory, 96: 40-69.

[9] Bernanke, Ben, and Mark Gertler. 1999. "Monetary Policy and Asset Price Volatility”, New Challenges for Monetary Policy: A Symposium Sponsored by the Federal Reserve Bank of Kansas City, Jackson Hole, Wyoming, August 26-28, 77-128. Kansas City: Federal Reserve Bank of Kansas City.

[10] Bernanke, Ben, and Mark Gertler. 2001. "Should Central Banks Respond to Movements in Asset Prices?", American Economic Review, 91 (2): 253-257.

[11] Bonchi, Jacopo. 2019. "Asset Price Bubbles with Low Interest Rates: Not All Bubbles are Alike", Eesti Pank Working Papers Series 1/2019.

[12] Bricker, Jesse, Dettling, Lisa, Henriques, Alice, Hsu, Joanne, Jacobs, Lindsay, Moore, Kevin, Pack, Sarah, Sabelhaus, John, Thompson, Jeffrey and Richard Windle. (2017). "Changes in U.S. Family Finances from 2013 to 2016: Evidence from the Survey of Consumer Finances”, Federal Reserve Bulletin, 103 (3).

[13] Borio, Claudio, and Philip Lowe. 2002. "Asset Prices, Financial and Monetary Stability: Exploring the Nexus”, Bank for International Settlements (BIS) Working Paper 114.

[14] Bucks, Brian, Kennickell, Arthur, Mach, Traci and Kevin Moore. 2009. "Changes in U.S. Family Finances from 2004 to 2007: Evidence from the Survey of Consumer Finances”, Federal Reserve Bulletin, A1, 95. 
[15] Caballero, Ricardo, and Emmanuel Farhi. 2017. "The Safety Trap”, Review of Economic Studies, 85 (1): 223-274.

[16] Calvo, Guillermo. 1983. "Staggered Prices in a Utility-Maximizing Framework", Journal of Monetary Economics, 12 (3): 983-998.

[17] Cecchetti, Stephen, Genberg, Hans, Lipsky, John and Sushil Wadhwani. 2000. "Asset Prices and Central Bank Policy", Geneva Reports on the World Economy 2, Vol. 2. London: Centre for Economic Policy Research.

[18] Cúrdia, Vasco. 2015. "Why So Slow? A Gradual Return for Interest Rates”, Federal Reserve Bank of San Francisco Economic Letter, 2015-32, October 12, 2015.

[19] Cúrdia, Vasco, Ferrero, Andrea, Ng, Ging Cee and Andrea Tambalotti. 2015. "Has U.S. Monetary Policy Tracked the Efficient Interest Rate?”, Journal of Monetary Economics, 70, 72-83.

[20] Dong, Feng, Miao, Jianjun and Pengfei Wang. 2017. "Asset Bubbles and Monetary Policy", 2017 Meeting Papers 205, Society for Economic Dynamics.

[21] Eggertsson, Gauti, and Micheal Woodford, 2003. "The Zero Bound on Interest Rates and Optimal Monetary Policy”, Brookings Papers on Economic Activity: 139-211.

[22] Eggertsson, Gauti, Neil Mehrotra, and Lawrence Summers. 2016 . "Secular Stagnation in the Open Economy", American Economic Review: Papers \& Proceedings, 106 (5): 503-507.

[23] Eggertsson, Gauti, Mehrotra, Neil and Jacob Robbins. 2019. "A Model of Secular Stagnation: Theory and Quantitative Evaluation", American Economic Journal: Macroeconomics, $11(1): 1-48$.

[24] Farhi, Emmanuel, Jean Tirole. 2012. "Bubbly Liquidity”, Review of Economic Studies, 79 (2): 678-706.

[25] Galì, Jordi. 2014. "Monetary Policy and Rational Asset Price Bubbles", American Economic Review, 104 (3): 721-752.

[26] Galì, Jordi. 2020. "Monetary Policy and Bubbles in a New Keynesian Model with Overlapping Generations", NBER Working Paper No. 26796. 
[27] Gordon, Robert. 2015. "Secular Stagnation: A Supply Side View", American Economic Review, 105 (5), 54-59.

[28] Holston, Kathryn, Laubach, Thomas and John Williams. 2017. "Measuring the Natural Rate of Interest: International Trends and Determinants", Journal of International Economics, 108 (S): 59-75.

[29] Ikeda, Daisuke. 2013. "Monetary Policy and Inflation Dynamics in Asset Price Bubbles", Bank of Japan Working Paper Series 13-E-4, Bank of Japan.

[30] Ikeda, Daisuke, and Toan Phan. 2016. “Toxic Asset Bubbles”, Economic Theory, 61 (2): 241-271.

[31] International Monetary Found. 2003. "When Bubbles Burst", Washington, DC: IMF.

[32] International Monetary Found. 2020. "The Great Lockdown”, Washington, DC: IMF.

[33] Jordá, Óscar, Schularick, Moritz, and Alan Taylor. 2015. "Leveraged bubbles”, Journal of Monetary Economics, 76 (S): 1-20.

[34] Jordá, Óscar, Singh, Sanjay and Alan Taylor. 2020. "Longer-run Economic Consequences of Pandemics", NBER Working Paper No. 26934.

[35] Kiley, Micheal, and John Roberts. 2017. "Monetary Policy in a Low Interest Rate World", Brookings Papers on Economic Activity, 1: 317-396.

[36] Krugman, Paul. 1998. "It's Baaack: Japan's Slump and the Return of the Liquidity Trap", Brookings Papers on Economic Activity, 29 (2): 137-206.

[37] Laubach, Thomas, and John Williams. 2016. "Measuring the Natural Rate of Interest Redux”, Business Economics, 51 (2): 57-67.

[38] Martin, Alberto, and Jaume Ventura. 2011. "Theoretical Notes on Bubbles and the Current Crisis", IMF Economic Review 59 (1): 6-40.

[39] Martin, Alberto, and Jaume Ventura. 2012. "Economic Growth with Bubbles", American Economic Review, 102 (6): 3033-3058.

[40] Marx, Magali, Mojon, Benoit and François Velde. 2019. "Why have interest rates fallen far below the return on capital”, BIS Working Papers 794, Bank for International Settlements. 
[41] Miao, Jianjun, and Pengfei Wang. 2018. "Asset Bubbles and Credit Constraints", American Economic Review, 108 (9): 2590-2628.

[42] Piketty, Thomas, Saez, Emmanuel and Gabriel Zucman. 2018. "Distributional National Accounts: Methods and Estimates for the United States", The Quarterly Journal of Economics, 133 (2): 553-609.

[43] Samuelson, Paul. 1958. "An Exact Consumption-Loan Model of Interest with or without the Social Contrivance of Money", Journal of Political Economy, 66 (6), 467-482.

[44] Schmitt-Grohé, Stephanie, and Martin Uribe. 2016. "Downward Nominal Wage Rigidity, Currency Pegs, and Involuntary Unemployment”, Journal of Political Economy, 124: 14661514.

[45] Summers, Lawrence. 2014. "US Economic Prospects: Secular Stagnation, Hysteresis, and the Zero Lower Bound", Business Economists, 49 (2): 65-73.

[46] Tirole, Jean. 1985. "Asset Bubbles and Overlapping Generations", Econometrica, 53 (6), 1499- 1528

[47] Weil, Philippe. 1987. "Confidence and the Real Value of Money in an Overlapping Generations Economy", Quarterly Journal of Economics, 102 (1): 1-22.

[48] Wicksell, Knut. 1898. “Interest and Prices”, trans. R.F. Kahn, London: Macmillan, 1936.

\section{Appendix}

\section{A The Model Economy}

\section{A.1 Exogenous Productivity Growth}

I spell out a different version of the model in Section 3, in which the population is constant, but the economy still grows at a positive rate of $g$ because of the exogenous growth in productivity $\left(A_{t+1} / A_{t}=1+g\right)$. The growth rate of productivity is defined as that of the population in the main text to emphasize the similarity between the two models, which coincide substantially. In this case, 
the production technology of firms is

$$
Y_{t}=A_{t} L_{t}^{\alpha}
$$

while the labor demand is

$$
\frac{W_{t}}{P_{t}}=\alpha A_{t} L_{t}^{\alpha-1}
$$

The maximization problem of the representative household becomes ${ }^{24}$

$$
\max _{C_{t+1}^{m}, C_{t+2}^{o}, Q_{t+1 \mid t+1-j}^{B}} E_{t}\left\{\ln C_{t}^{y}+\beta \ln C_{t+1}^{m}+\beta^{2} \ln C_{t+2}^{o}\right\}
$$

s.t.

$$
\begin{gathered}
C_{t}^{y}=B_{t}^{y}=\frac{A_{t+1} D+\delta E_{t} P_{t+1 \mid t+1}^{B}}{\left(1+r_{t}\right)} \\
C_{t+1}^{m}=Y_{t+1}+\delta P_{t+1 \mid t+1}^{B}-\left(1+r_{t}\right) B_{t}^{y}-B_{t+1}^{m}-\sum_{j=0}^{\infty} P_{t+1 \mid t+1-j}^{B} Q_{t+1 \mid t+1-j}^{B} \\
C_{t+2}^{o}=\left(1+r_{t+1}\right) B_{t+1}^{m}+(1-\delta) \sum_{j=0}^{\infty} P_{t+2 \mid t+1-j}^{B} Q_{t+1 \mid t+1-j}^{B} .
\end{gathered}
$$

The assumptions about the household sector are the same of Section 3 , except for the quantity of bubbly assets that does not grow anymore and the exogenous debt limit that becomes $A_{t+1} D$. As income is positively affected by productivity growth, the ability to repay debt in middle age is enhanced allowing young households to raise more funds. The Euler equation is unaffected by the new assumptions, while the price of a generic bubbly asset is now given by

$$
P_{t \mid t-j}^{B}=(1-\delta) \beta E_{t}\left[\left(\frac{C_{t}^{m}}{C_{t+1}^{o}}\right) P_{t+1 \mid t-j}^{B}\right] .
$$

All the other assumptions of the benchmark model are unchanged, in particular the DNWR and the monetary policy are still described by equations $(10)$ and $(11)$. As regards the two markets for financial assets, the equilibrium condition in the market for bubbles is still [13, but now the aggregate supply of bubbles is one because the size of generations is normalized to one $\left(Q_{t}^{B}=\right.$ $\left.\delta \sum_{j=0}^{\infty}(1-\delta)^{j}=1\right)$. Notwithstanding, the bubble indexes normalized by productivity are equiv-

\footnotetext{
${ }^{24}$ The borrowing constraint binds because

$$
A_{t} D_{t-1}<\frac{1}{1+\beta(1+\beta)}\left[Y_{t}-\beta(1+\beta) \delta P_{t \mid t}^{B}\right] .
$$
}


alent to those normalized in terms of $N_{t-1}$ of Section 3 .

$$
\begin{gathered}
\tilde{P}_{t}^{B}=\tilde{B}_{t}+\tilde{U}_{t}=\beta(1+g)\left[\left(\frac{C_{t}^{m}}{C_{t+1}^{o}}\right) \tilde{B}_{t+1}\right] \\
\tilde{B}_{t}=\frac{1}{A_{t}} \delta \sum_{j=1}^{\infty}(1-\delta)^{j} P_{t \mid t-j}^{B} \\
\tilde{U}_{t}=\frac{\delta P_{t \mid t}^{B}}{A_{t}}
\end{gathered}
$$

likewise the conditions governing the credit market,

$$
\begin{gathered}
\tilde{D}_{t}^{c}=\tilde{B}_{t}^{y}=\left(\frac{1+g}{1+r_{t}}\right)\left(D+\tilde{U}_{t+1}\right) \\
\tilde{S}_{t}^{c}=\tilde{B}_{t}^{m}=\frac{\beta}{1+\beta}\left(\tilde{Y}_{t}-D\right)-\left(\tilde{B}_{t}+\tilde{U}_{t}\right) \\
\left(1+r_{t}\right)=(1+g)\left[\frac{(1+\beta)\left(D+\tilde{U}_{t+1}\right)}{\beta\left(\tilde{Y}_{t}-D-\tilde{U}_{t}-\tilde{B}_{t}\right)-\left(\tilde{B}_{t}+\tilde{U}_{t}\right)}\right] .
\end{gathered}
$$

The symbol $\sim$ denotes variables normalized by productivity and all the expectation terms are suppressed because perfect foresight is assumed.

\section{A.2 Capital}

I extend the model of Appendix A.1 by assuming middle-aged households can also invest in capital, which deteriorates at the rate $\delta$, along with risk-free and bubbly assets. Capital is rented out to firms in the same period in which investment takes place. Hence, the middle generation receives the rental income. The production technology of firms is given by the Cobb-Douglas function

$$
Y_{t}=A_{t} K_{t}^{1-\alpha} L_{t}^{\alpha}
$$

and perfect competition in the market for inputs implies

$$
\frac{W_{t}}{P_{t}}=\alpha \frac{Y_{t}}{L_{t}}
$$

and

$$
r_{t}^{k}=(1-\alpha) \frac{Y_{t}}{K_{t}}
$$


where $r_{t}^{k}$ is the rental rate of capital. The household's maximization problem is:

$$
\max _{C_{t+1}^{m}, C_{t+2}^{o}, K_{t+1}, Q_{t+1 \mid t+1-j}^{B}} E_{t}\left\{\ln C_{t}^{y}+\beta \ln C_{t+1}^{m}+\beta^{2} \ln C_{t+2}^{o}\right\}
$$

s.t.

$$
\begin{gathered}
C_{t}^{y}=B_{t}^{y}=\frac{A_{t+1} D+\delta E_{t} P_{t+1 \mid t+1}^{B}}{\left(1+r_{t}\right)} \\
C_{t+1}^{m}=Y_{t+1}+\delta P_{t+1 \mid t+1}^{B}-\left(1+r_{t}\right) B_{t}^{y}-K_{t+1}-B_{t+1}^{m}-\sum_{j=0}^{\infty} P_{t+1 \mid t+1-j}^{B} Q_{t+1 \mid t+1-j}^{B} \\
C_{t+2}^{o}=\left(1+r_{t+1}\right) B_{t+1}^{m}+(1-\delta)\left[\sum_{j=0}^{\infty} P_{t+2 \mid t+1-j}^{B} Q_{t+1 \mid t+1-j}^{B}+K_{t+1}\right],
\end{gathered}
$$

where $Y_{t}=\frac{W_{t}}{P_{t}} L_{t}+r_{t}^{k} K_{t}$. In addition to equations 5 and 36 , we have an optimality condition for capital,

$$
\left(1-r_{t}^{k}\right) \frac{1}{C_{t}^{m}}=\beta(1-\delta) E_{t} \frac{1}{C_{t+1}^{o}}
$$

which, combined with the Euler equation, delivers a no-arbitrage condition relating the capital rental rate to the real interest rate:

$$
r_{t}^{k}=\frac{r_{t}+\delta}{\left(1+r_{t}\right)} \geq 0
$$

Although the marginal product of capital cannot be negative, this only imposes a lower bound on the real interest rate, $r_{t} \geq-\delta$, without preventing it from turning negative. Finally, the demand for credit is

$$
\tilde{D}_{t}^{c}=\tilde{B}_{t}^{y}=\left(\frac{1+g}{1+r_{t}}\right)\left(D+\tilde{U}_{t+1}\right)
$$

while the credit supply becomes

$$
\tilde{B}_{t}^{m}=\frac{\beta}{1+\beta}\left(\tilde{Y}_{t}-D-\tilde{K}_{t}\right)-\left(\tilde{U}_{t}+\tilde{B}_{t}\right)-(1+g) \frac{(1-\delta) \tilde{K}_{t+1}}{(1+\beta)\left(1+r_{t}\right)}
$$

Apart from the additional condition (37) and productivity growth instead of population growth, the model and the related results are the same of Section 3 . In particular, the introduction of capital as an alternative store of value reduces the credit supply, but the real interest can be negative anyway. Furthermore, the bubble exerts an upward pressure on the real interest rate through the same channels outlined in the main text. The interpretation of the bubble only changes in this setting, because, though it is still a specific asset, it can now be interpreted as the component of the capital value 
unrelated to the fundamentals. Therefore, the creation of the bubble in middle age is associated with the investment in new capital, while its destruction in old age comes from the obsolescence of capital. This interpretation helps to clarify why nothing changes, compared to the benchmark model of Section 3 .

The problem of excess saving underlying a negative natural interest rate does not necessarily lead to excessive capital, because the investment in capital carries some risk, though not modelled here ${ }^{25}$ In contrast, an excess of saving results in excessive demand for "safe" assets (Caballero and Fahri, 2017), like the risk-free bonds in my model. Hence, the bubble, whether attached to risky capital or not, absorbs the extra demand for safe assets by diverting funds towards risky assets. This is shown clearly in Section 5 , in which I study risky asset price bubbles.

\section{B Steady State Equilibrium}

\section{B.1 Existence of the Bubbly Equilibrium}

This proof is very close to that in Galì (2014, Appendix 2), so I refer to that paper for further details. $H$ mapping has the following properties.

1. $H(B, U) \geq 0$ is twice continuously differentiable for $0 \leq B<\bar{B}(U)$, where $\bar{B}(U)=$ $\frac{\beta}{1+\beta}(Y-D)-U$. If $B>\bar{B}(U), H(B, U)<0$.

2. The derivatives of $H(B, U)$ with respect to $B_{t}$ are

$$
\frac{\partial H(B, U)}{\partial B_{t}}=\frac{\beta(1+\beta)(D+U)(Y-D)}{[\beta(Y-D-U-B)-(U+B)]^{2}}>0
$$

and

$$
\frac{\partial^{2} H(B, U)}{\partial B_{t}^{2}}=\frac{2 \beta(1+\beta)^{2}(D+U)(Y-D)}{[\beta(Y-D-U-B)-(U+B)]^{3}}>0 .
$$

The second inequality holds for $0 \leq B<\bar{B}(U)$ and $\lim _{B \rightarrow \bar{B}(U)} H(B, U)=+\infty$.

\footnotetext{
${ }^{25}$ In this respect, it is worthy to note that the return on capital, unlike risk-free interest rates, has been stable over the last forty years (Marx et al., 2019).
} 
3. The derivatives of $H(B, U)$ with respect to $U$ are

$$
\begin{gathered}
\frac{\partial H(B, U)}{\partial U}=\frac{(1+\beta)(D+2 U+B)[\beta(Y-D-U-B)-(U+B)]}{[\beta(Y-D-U-B)-(U+B)]^{2}}+ \\
\frac{(1+\beta)^{2}(D+U)(U+B)}{[\beta(Y-D-U-B)-(U+B)]^{2}}>0
\end{gathered}
$$

and

$$
\begin{aligned}
\frac{\partial^{2} H(B, U)}{\partial U^{2}}= & \frac{2(1+\beta)[\beta(Y-D-U-B)-(U+B)]^{2}}{[\beta(Y-D-U-B)-(U+B)]^{3}}+ \\
& \frac{2(1+\beta)^{2}(D+2 U+B)[\beta(Y-D-U-B)-(U+B)]}{[\beta(Y-D-U-B)-(U+B)]^{3}}+ \\
& \frac{2(1+\beta)^{3}(D+U)(U+B)}{[\beta(Y-D-U-B)-(U+B)]^{3}}>0 .
\end{aligned}
$$

Both inequalities hold for $0 \leq B<\bar{B}(U)$ and $\lim _{B \rightarrow \bar{B}(U)} H(B, U)=+\infty$.

4. The mixed second derivative is

$\frac{\partial H(B, U)}{\partial B_{t} \partial U}=\frac{\beta(1+\beta)(Y-D)\{[\beta(Y-D-U-B)-(U+B)]+2(1+\beta)(D+U)\}}{[\beta(Y-D-U-B)-(U+B)]^{3}}$

and it is positive for $0 \leq B<\bar{B}(U)$ and $\lim _{B \rightarrow \bar{B}(U)} H(B, U)=+\infty$.

Consider first the case $U=0$. Equation (22) becomes

$$
B_{t+1}=\frac{(1+\beta) D B_{t}}{\beta\left(Y-D-B_{t}\right)-B_{t}}=H\left(B_{t}, 0\right) .
$$

A solution to this equation is the bubbleless steady state equilibrium $(B, U)=(0,0)$. A bubbly steady state equilibrium $\left(B^{U}, 0\right)$ with $B^{U} \in\left(0, Y^{f}\right)$ is another solution of the equation if

$$
\frac{\partial H(0,0)}{\partial B_{t}}=\frac{(1+\beta) D}{\beta(Y-D)}<1
$$

This condition, which is necessary and sufficient for the existence of the bubbly equilibrium $\left(B^{U}, 0\right)$, derives from property 2 and it can be alternatively expressed as

$$
D<\frac{\beta}{1+\beta}(Y-D)
$$


Figure 6: Old bubble dynamics

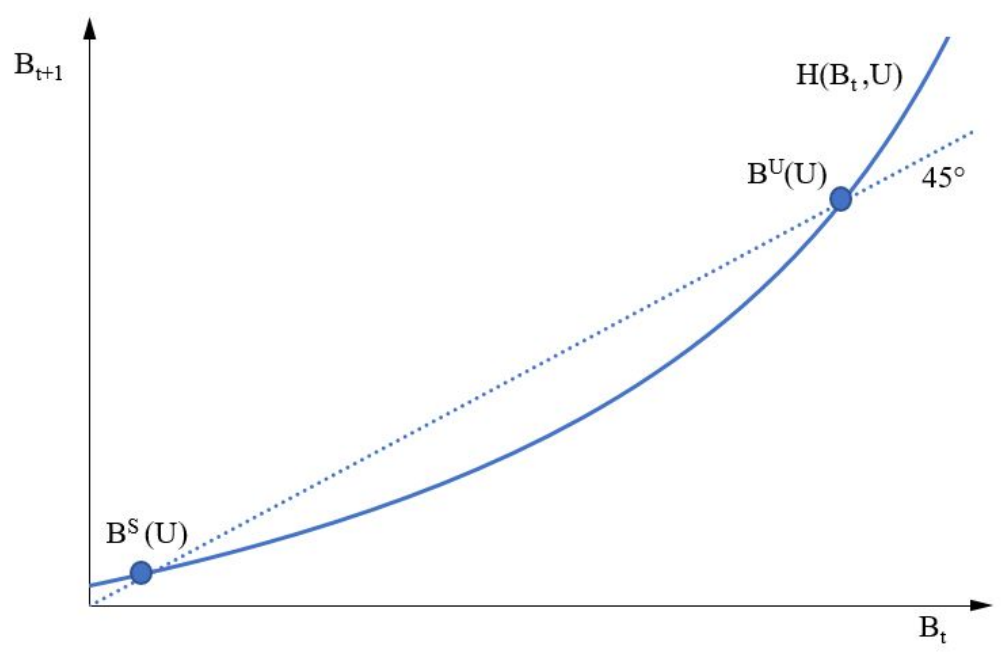

The bubbly equilibrium is unstable for the same reasons expressed in Galì (2014).

Sufficiency: Assume condition (23) holds. Given property 3 and the continuity of $H$, there are two steady state equilibria $B^{U}(U)$ and $B^{S}(U)$ for any $U \in(0, \bar{U})$ with $\bar{U}=[(1+2 \beta) D-\beta Y]^{2} /[4 \beta(1+\beta)(Y-D)]$. $B^{U}(U)$ and $B^{S}(U)$ have the same stability properties of the equilibria in Galí (2014), and $B^{U}(U)>$ $B^{S}(U)$. These two equilibria are depicted in Figure 6

Necessity: The proof is equivalent to that in Galì (2014).

\section{B.2 Stationarity of the Old Bubble}

Taken at $t$, equation 22) becomes

$$
B_{t}=\frac{(1+\beta)\left(D+U_{t}\right)\left(U_{t-1}+B_{t-1}\right)}{\beta\left(Y-D-U_{t-1}-B_{t-1}\right)-\left(U_{t-1}+B_{t-1}\right)} .
$$

Denoting log-linearized variables by lowercase letters, the log-linearized version of the equation above is

$$
b_{t}=\varphi v_{b} b_{t-1}+\psi_{u} u_{t}+\varphi v_{u} u_{t-1},
$$


where $\varphi=\frac{\beta(Y-D)}{[\beta(Y-D-U-B)-(U+B)]}, v_{b}=\frac{B}{U+B}, \psi_{u}=\frac{U}{D+U}$ and $v_{u}=\frac{U}{U+B}$. The condition for the stationarity of the old bubble is

$$
\varphi v_{b}=\left[\frac{\beta(Y-D)}{\beta(Y-D-U-B)-(U+B)}\right]\left(\frac{B}{U+B}\right)<1
$$

and it coincides with that for the stability of the bubbly equilibrium

$$
\frac{\partial H(B, U)}{\partial B}=\left[\frac{\beta(Y-D)}{\beta(Y-D-U-B)-(U+B)}\right]\left[\frac{(1+\beta)(D+U)}{\beta(Y-D-U-B)-(U+B)}\right]<1 .
$$

Indeed,

$$
\left(\frac{B}{U+B}\right)=\left[\frac{(1+\beta)(D+U)}{\beta(Y-D-U-B)-(U+B)}\right]
$$

follows directly from equation (22) taken at the bubbly steady state and so

$$
\frac{\partial H(B, U)}{\partial B}=\left[\frac{\beta(Y-D)}{\beta(Y-D-U-B)-(U+B)}\right]\left(\frac{B}{U+B}\right)=\varphi v_{b} .
$$

\section{B.3 Calibrated Model}

I perform here a calibration of the model in Section 3 The aim of this exercise is not to measure the impact of a bubble on risk-free interest rates, because the model is too stylized to provide an accurate quantitative evaluation. Rather, I aim to show that the bubble size, necessary to bring the economy from the LIR to the FEB, is reasonable according to a standard calibration of the model. Table (1) contains the calibrated values for the parameters. These values are in annual terms, and they have to be converted to 20 years that is the length of a generation. A similar consideration applies to the other calibrations of the model described in the paper.

Labor supply is 1 to normalize all variables in terms of potential output, which coincides with the current output in the FEB. I use the average real GDP growth rate in the years 2000-2020, computed by the IMF (2020) for the advanced economies, to calibrate $g^{26} \gamma=1$ falls in the range of values found by Schmitt-Grohé and Uribe (2016), while I set $D$ to the value of the quantitative model of Eggertsson et al. (2019). The remaining parameters are standard.

In a bubbleless economy, this calibration delivers $r_{n b}^{f}=-0.004(-0.4 \%)$, which is very close

\footnotetext{
${ }^{26}$ The group of the "advanced economies" is composed of the following countries: Australia, Austria, Belgium, Canada, Cyprus, Czech Republic, Denmark, Estonia, Finland, France, Germany, Greece, Hong Kong SAR, Iceland, Ireland, Israel, Italy, Japan, Korea, Latvia, Lithuania, Luxembourg, Macao SAR, Malta, Netherlands, New Zealand, Norway, Portugal, Puerto Rico, San Marino, Singapore, Slovak Republic, Slovenia, Spain, Sweden, Switzerland, Taiwan Province of China, the United Kingdom and the United States.
} 
Table 1: Parameters and variables

\begin{tabular}{lll}
\hline Parameters & Values & Description \\
\hline$\beta$ & 0.987 & Discount factor \\
$\alpha$ & 0.7 & Labor share \\
$D$ & 0.23 & Collateral constraint \\
$g$ & 0.015 & Economy's growth rate \\
$\Pi^{*}$ & 1 & Inflation target \\
$\phi_{\pi}$ & 2 & Taylor coefficient \\
$\gamma$ & 1 & Wage rigidity \\
$\bar{L}$ & 1 & Labor supply \\
& & \\
\hline Variables & & FEB \\
\hline$Y$ & LIR & 1 \\
$\Pi$ & 0.94 & 1 \\
$r$ & 1 & 0 \\
$r^{f}$ & 0 & 0 \\
$i$ & -0.004 & 0 \\
$P^{B}=B+U$ & 0 & 0.027 \\
\hline
\end{tabular}

to the average US natural interest rate over the period 2000-2019 (-0.67\%) estimated at a quarterly frequency by Cúrdia (2015). The estimates of Cúrdia (2015) are a useful benchmark, because the theoretical model used for their computation incorporates a short-term definition of the natural interest rate that fits with that in my model. For the assumed zero inflation target $\left(\Pi^{*}=1\right)$, the level of natural interest rate obtained is compatible with a LIR, which corresponds to point $B$ in Figure 7 The figure is plotted by using the calibrated values.

We know from Section 4.1 .1 that the economy stays at the FEB if the natural interest rate is non-negative/positive (equation (31)). More precisely, a zero natural rate of interest is sufficient to move the economy from the initial LIR to the FEB, although the nominal interest rate is still stuck at the ZLB in the final equilibrium. This is depicted by the FEB (point $A$ ) that occurs at the AD kink in Figure 7 Hence, the exercise aims to find the value of the aggregate bubble necessary to make the natural interest rate zero. This value is 0.027 , and it is reported along with the values of the other variables in Table 1

As the minimum size of the bubble required for the transition to the FEB is only $2.7 \%$ of GDP and the corresponding increase in wealth relative to the LIR is $11.8 \%{ }^{27}$ the theoretical results of ${ }^{27}$ This is $\left(C_{F E B}^{o}-C_{L I R}^{o}\right) / C_{L I R}^{o}=(U+B) / D$. 
Figure 7: FEB in the calibrated model

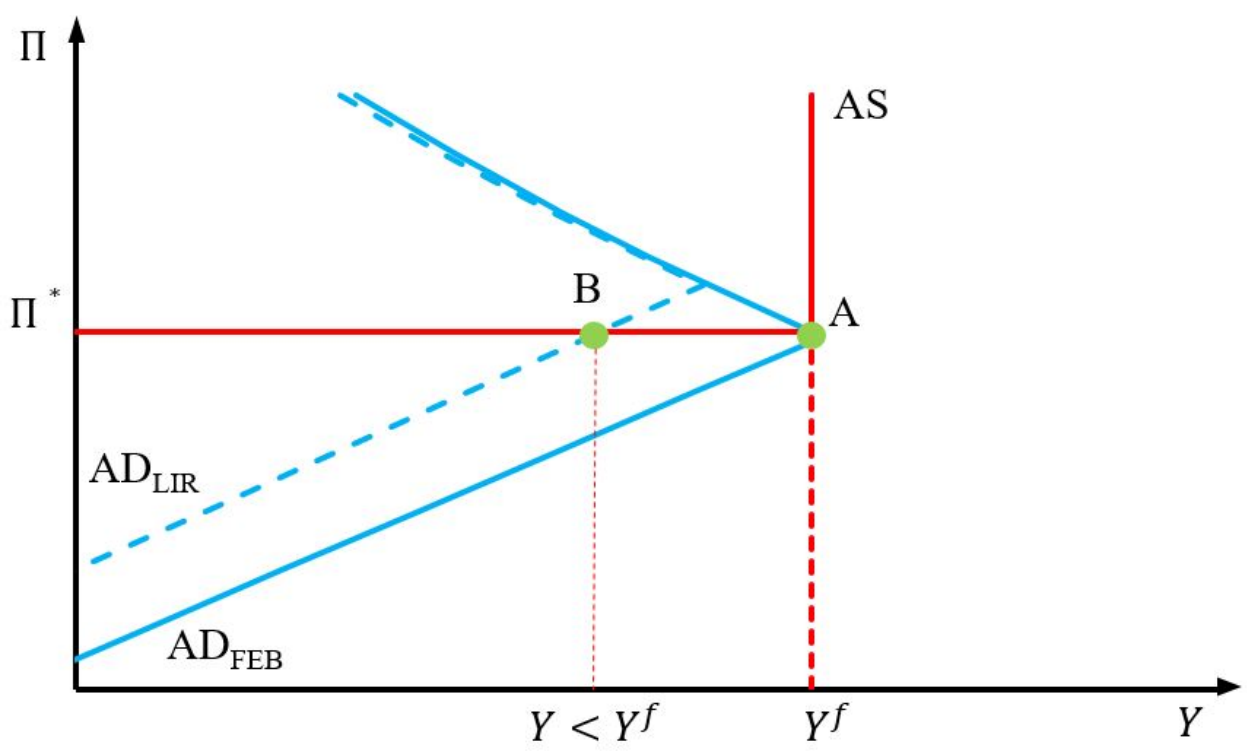

Section 4.1.1 are not restricted to an extreme calibration of the model, in particular of the bubble size, but they hold for a standard calibration and for a reasonably large aggregate bubble.

\section{B.4 Welfare Analysis}

\section{B.4.1 FE vs FEB}

I perform several calibrations of the model to determine the sign of equation 32 , which is governed by $\beta, D$ and $P^{B}=U+B$. I first study how the difference $U_{F E B}-U_{F E}$ varies according to the bubble size for different calibrations of $\beta$. I set, in this case, $D=0.22$, which is very close to the value of Eggertsson et al. (2019) in their quantitative model (0.23) ${ }^{28}$ Figure 8 , in which the bubble size is plotted against the welfare level, presents the results of my first numerical exercise. $U_{F E}$ is depicted by a horizontal line because it is independent of the bubble, and the maximum size of the bubble varies with $\beta$.

The difference between $U_{F E B}$ and $U_{F E}$ is always negative, and the lifetime utility in the FEB declines as the bubble enlarges, widening the gap with that in the FE. The intuition underlying these

\footnotetext{
${ }^{28} \mathrm{I}$ also set $\gamma=1, \alpha=0.7, \Pi^{*}=1, \phi_{\pi}=2$ and $g=0.023$, because this calibration corresponds to a FE. However, other calibrations of these parameters can be employed, as long as they deliver a FE in the bubbleless economy, without any difference in the allocation of resources and the implied welfare level.
} 
Figure 8: Bubble size and welfare for different calibrations of $\beta$
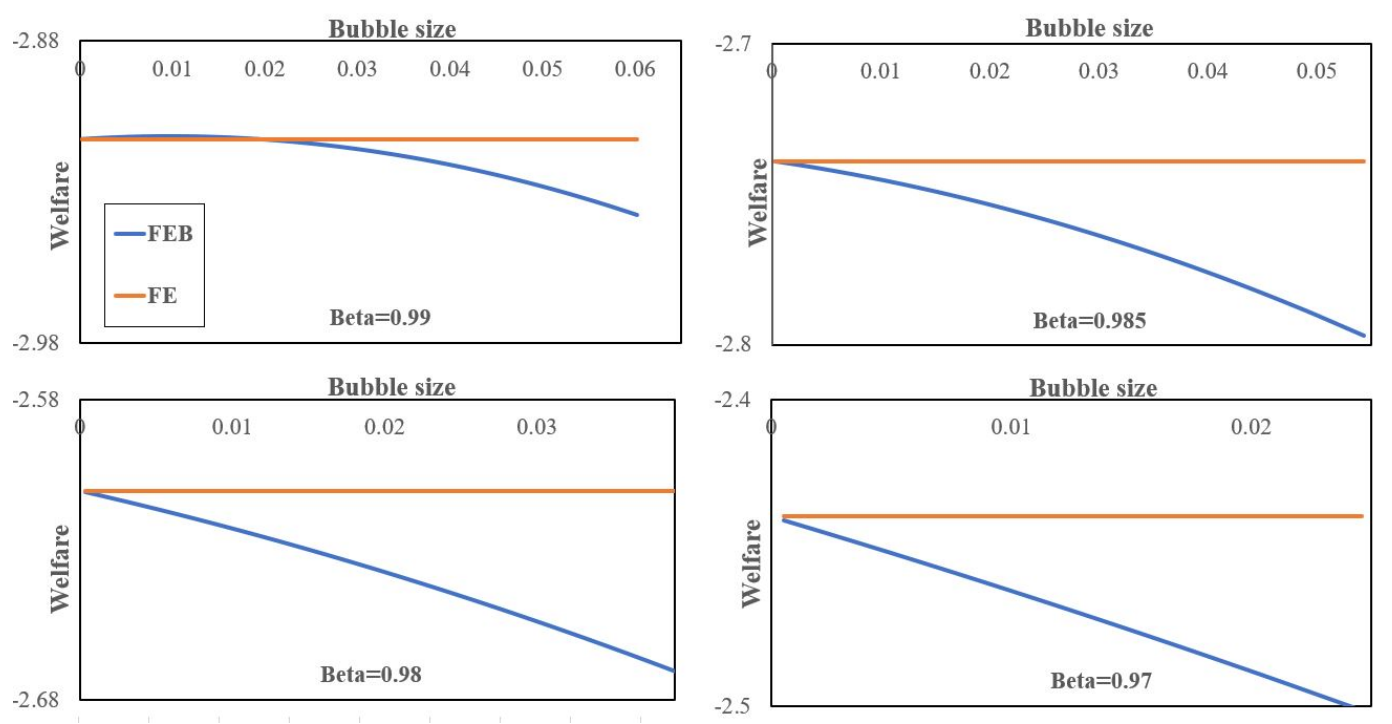

results is straightforward. In the FEB, the consumption gains in old age increase with the bubble size, like the consumption losses in young age (equation (32)). $U_{F E B}$ is lower than $U_{F E}$, because the losses are given a greater weight than the gains $(\beta<1)$. Furthermore, the marginal effect on $U_{F E B}$ of a lower $C^{y}$ increases with the bubble size, while the marginal effect on $U_{F E B}$ of a higher $C^{o}$ declines. This explains why a larger bubble widens the negative gap between $U_{F E B}$

A special case is the calibration $\beta=0.99$ that delivers $U_{F E B}>U_{F E}$ for small bubble sizes (top left panel of Figure 87. Smaller bubbles reduce the consumption losses in young age and the consumption gains in old age, but the negative effect on the size of gains is compensated by a high $\beta$ that implies a great evaluation of them. On the other hand, the higher $\beta$, the higher is the supply of credit from middle-age households and so the consumption of young ones. This mitigates the marginal impact on $U_{F E B}$ of a reduction in the young age consumption (the term $(1+\beta) / \beta$ in equation (32) decreases).

The case of $\beta=0.99$ does not restrict the conclusion of the first numerical exercise. Rather, a second exercise, in which I purposely choose this calibration of $\beta$ but different calibrations of $D$, proves the general validity of my result. Figure plots the second exercise 9 and its top left panel is identical to that of Figure 8 because of the two calibrations coincide. The range of values chosen for $D$ is a plausible calibration of the debt limit, given that the value set by Eggertsson et al. (2019) is exactly in the middle. Finally, a lower value of $\beta$ does not change the results because it would imply 
Figure 9: Bubble size and welfare for different calibrations of $D$
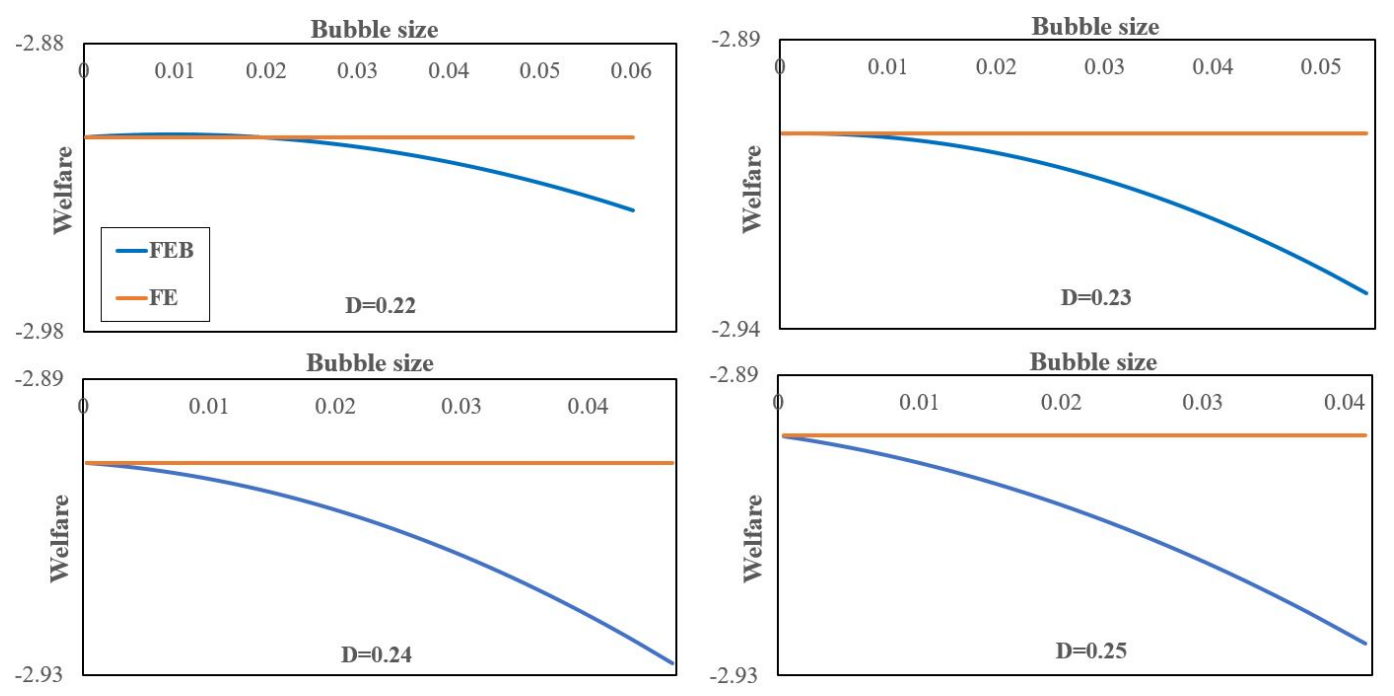

a lower consumption level at young age. This, in turn, would amplify the marginal effect on $U_{F E B}$ of a reduction in $C^{y}$.

\section{B.4.2 LIR vs FEB}

I employ the following procedure to compute equation 33 numerically. I calibrate in a standard way (see Table 1 the parameters determining the natural interest rate: $\beta, D, g$ and $Y^{f}$; and I fix $\Pi^{*}=1$ so that I can take the empirical estimates for $\gamma$ of Schmitt-Grohé and Uribe (2016), who find this parameter ranging approximately from 1 to 1.022. For this range of values of $\gamma$, I calculate all the values of the bubbly natural interest rate consistent with a FEB. Finally, for any given $\left(1+r_{F E B}^{f}\right)$, I compute how the difference in 33 varies according to $\gamma \Pi^{*} 29$ Figure 10 in which each red line is a different function corresponding to a specific value of the natural rate of interest, depicts the result of my numerical exercise. The figure shows that $C_{F E B}^{y}-C_{L I R}^{y}$ is always positive for all the calibrations of $\gamma \Pi^{*}$ and $\left(1+r_{F E B}^{f}\right)$.

\footnotetext{
${ }^{29}$ I compute specifically the term $D\left[1-\gamma \Pi^{*}\left(1+r_{F E B}^{f}\right)\right]+U$, which governs the difference in 33 , to simplify the computation. The value of $U$ employed is that corresponding to each value of $\left(1+r_{F E B}^{f}\right)$.
} 
Figure 10: Consumption of young households

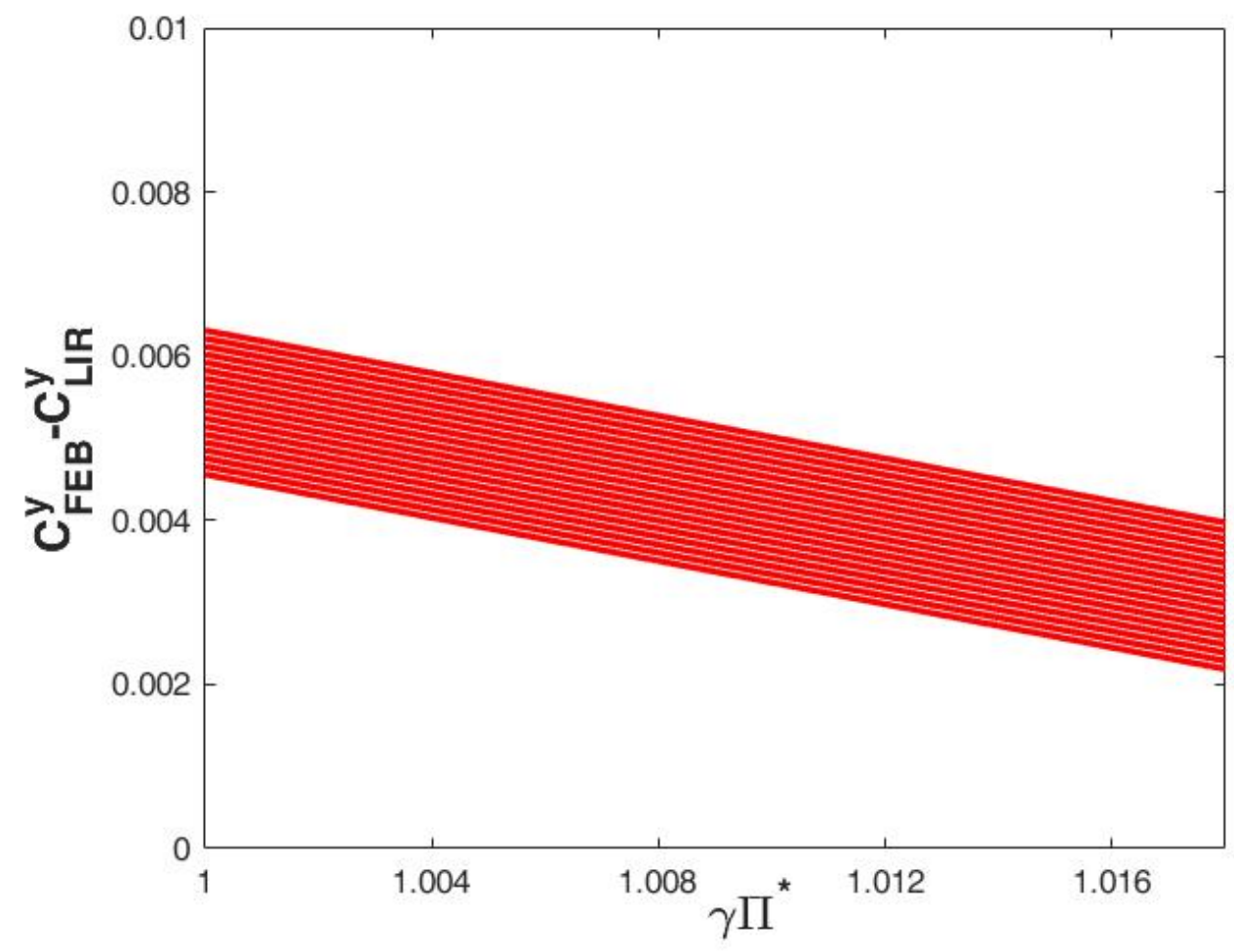

